\title{
Sa skya Paṇdita's Classification of Arguments by Consequence Based on the Type of the Logical Reason: Editorial Conundrum and Mathematics for Commentators
}

\author{
Pascale Hugon ${ }^{1}$ (D) \\ Published online: 17 August 2018 \\ (C) The Author(s) 2018
}

\begin{abstract}
This paper examines a passage of the eleventh chapter of the Rigs gter of Sa skya Pandita (1182-1251) on the division of arguments by consequence (thal 'gyur) of the form "Because S is P, it follows that it is Q" with respect to the type of relation between $\mathrm{P}$ and $\mathrm{Q}$. This passage appears in quite different versions in several available recensions of the Rigs gter, all of which are problematic to some extent. The different interpretations of the commentators can be shown to derive from their reliance on different versions of the text, which they strove to make sense of through two distinct strategies. Following up on the examination of a division of arguments by consequence along the same line in the works of Sa skya Pandita's Tibetan predecessors, in particular Phya pa Chos kyi seng ge (1109-1169) and mTshur ston gZhon nu seng ge (ca. 1150-1210) (see Hugon, in J Indian Philos 44(5):883-938, 2016b), I evaluate the diverging versions of the Rigs gter against a coherent logical scenario founded on Sa skya Pandita's discussion pertaining to the types of logical reasons in inference in the tenth chapter of his work and comparison with the classification by Phya pa. I offer a hypothesis regarding the genesis of the problematic versions of the passage on the classification of consequences in the Rigs gter based on the comparison with the classification found in mTshur ston's epistemological work. I propose that the composition of this portion of the Rigs gter might have involved a textual reuse of mTshur ston's classification, even though mTshur ston and Sa skya Pandita disagree on background issues. This very disagreement imposed changes to the reused text that led to problematic readings.
\end{abstract}

Keywords Sa skya Pạ̣dita t thal 'gyur . Tshad ma rigs gter · Tibet · Epistemology

Pascale Hugon

pascale.hugon@oeaw.ac.at

1 Austrian Academy of Sciences, OEAW, IKGA, Hollandstrasse 11-13, 1020 Vienna, Austria 


\section{Introduction}

This paper is a follow-up to a study previously published in the Journal of Indian Philosophy, which examined the classification of arguments by consequence (thal 'gyurlthal ba) on the basis of the type of the logical reason in the works of the Tibetan logician Phya pa Chos kyi seng ge and the modified model adopted by his successors gTsang nag pa brTson 'grus seng ge (?-after 1195) and mTshur ston gZhon nu seng ge. ${ }^{1}$ These authors consider consequences of the form:

\section{Because $S$ is $P$, it follows that it is $Q$}

Their reverse form (the direct proof that they induce) is:

Since $S$ is not- $Q$, then it is not- $P^{2}$

The classification under consideration pertains to the type of the logical reason in the consequence, i.e., the property $P{ }^{3}$ The type of the logical reason is defined by the relation between $P$ and the property $Q$ that is derived from it through entailment (for instance, if $P$ is the property "produced" and $Q$ is the property "impermanent," the type of the logical reason is "essential property"). These authors rely on a list of types that originates from a previous discussion in the context of inference-foroneself, which establishes which types are legitimate, that is, enable the ascertainment of the logical reason's triple characterization (which defines it as a correct logical reason). In the context of discussing arguments by consequence, the authors first divide the types in this list according to whether they can or cannot properly be used as a logical reason in a probative consequence. They examine whether a consequence whose logical reason is a property $P$ of a given type is genuine (this is the case if the required features obtain for the addressee of the argument) and induces a reverse form that is a correct direct proof (rang rgyud). ${ }^{4}$ The types that are fit to being used in a consequence are further subdivided by considering whether the type of the logical reason in the reverse form, i.e., the type of not- $Q$, is the same or not the same as the type of the logical reason in the consequence, i.e., of $P$. I term the former "symmetric" and the latter "asymmetric."

\footnotetext{
${ }^{1}$ Hugon (2016b). In order to avoid repeating the views of these authors and the main logical issues already discussed in this earlier paper, it will frequently be referred to below. The published version of the paper is available at https://link.springer.com/article/10.1007/s10781-015-9285-4; thanks to the Springer Nature SharedIt initiative, it can be viewed freely at http://rdcu.be/pCG6.

${ }^{2}$ For instance, the consequence "Because there is no fire on the mountain pass, it follows that there is no smoke" induces the reverse form "Since there is smoke on the mountain pass, then there is fire." On the constitutive elements of arguments by consequence as well as the relation between a consequence and its reverse form, see Hugon (2013, 2016a).

${ }^{3}$ The use of the term "logical reason" for the element $P$ in the argument by consequence is metaphorical. The term refers to the element put forward as the evidence (accepted by the opponent) from which the conclusion of the consequence $(Q)$ is derived, but it does not imply that $P$ itself is a correct logical reason, i.e., a triply characterized reason for proving $Q$.

${ }^{4}$ For more details on the definition of "genuine consequences" and "probative consequences," see Hugon (2013, 2016a). "Non-probative consequences," also called "refuting consequences," i.e., genuine consequences that merely refute the opponent but do not induce a correct direct proof, are not considered here.
} 
This second division is a mere curiosity without logical significance, which nonetheless appears to have fascinated the authors carrying out such a classification.

Sa skya Pandita Kun dga' rgyal mtshan is well known to have massively criticized his Tibetan predecessors in the field of epistemology. His discussion of arguments by consequence is not an exception and displays notable disagreement with earlier definitions and divisions. However, in the eleventh chapter of his Rigs gter, on inference-for-others, Sa skya Pandita also proposes a classification of correct arguments by consequence along the line sketched out above, differentiating the types that "induce a probative argument" (sgrub byed 'phen pa) and those that do not and, among the former, symmetric and asymmetric types (see 1.2.3 in the structure presented in Appendix 1). ${ }^{5}$ This passage was previously studied by Onoda (1986, pp. 72-82), who noted that the version found in the sDe dge print contains problematic readings and that there are significant variants between this version and other versions of the Rigs gter, in particular the Mongol printed edition (hor par $m a$ ). Onoda discussed the interpretations of Go rams pa bSod nams seng ge (14291489) and gSer mdog pan chen Śākya mchog ldan (1428-1507), who disagree in their respective commentaries on the Rigs gter as to the number of types taken into consideration by Sa skya Pandita in each category. Onoda concluded on the impossibility to settle the question of Sa skya Pandita's own classification. The comparative recensions (dpe bsdur ma) of the Rigs gter published in 2005 and 2007 that provide the variant readings from early versions of the text (a Mongol print, a manuscript from Zhwa lu and a manuscript from $\mathrm{Lu}$ phu), newly available versions of the text, as well as the works of Sa skya Pandita's predecessors in which this classification is also found are valuable material to consider afresh this problematic passage.

This paper offers a new attempt at solving the editorial and interpretative conundrum that this passage of the Rigs gter presents by bringing together logical clues, text-critical analysis and comparative analysis. I consider in Sect. 1 Sa skya Pandita's discussion on the legitimate types of logical reasons in the chapter of the Rigs gter on inference-for-oneself (a passage for which there are neither problematic readings nor significant variations between the available versions). This discussion provides a list of types that acts as the background for the classification of consequences and thus can serve as evidence for assessing the consistency of the diverging versions in this subsequent passage. Turning to these diverging versions in Sect. 2, I discuss the classification proposed in each and point out the respective problems. These problems include logical mistakes, lack of coherence between the verses and the autocommentary and inconsistency with the discussion of legitimate types in the chapter on inference-for-oneself. The various strategies and solutions adopted by commentators of the Rigs gter are discussed separately in Sect. 3. Throughout Sects. 1 and 2, I pay particular attention to the similarities and differences with respect to the parallel discussions in the works of Sa skya Pandita's predecessors, in particular the classification of Phya pa, whose position on

\footnotetext{
5 For Sa skya Pandita, "correct consequences" are those in which the premises accepted by the opponent lead to an unwanted consequence. They correspond to what Phya pa calls "genuine consequences." Cf. Rigs gter XI, 419,11-12: thal ba yang dag gi mtshan nyid ni khas blangs kyi rtags las mi 'dod pa'i bsgrub bya 'phen pa'o $\|$ (all references to the Rigs gter given in this form are to Rigs gter dpe bsdur ma 1).
} 
legitimate types is the closest to the one proposed by Sa skya Pandita. In the conclusion, I envisage which scenario would best explain the various versions of the Rigs gter pertaining to the classification of consequences. I propose a hypothesis based on the observation of textual similarities with the parallel discussion in the sGron ma of mTshur ston, with whom Sa skya Pandita however disagrees on the question of legitimate types.

The aim of this paper is not only to shed light on the reading of this particular passage on the classification of consequences and on Sa skya Pandita's views, but, indirectly, to prompt a methodological reflection on the resources available to ancient and modern scholars to understand and interpret problematic texts.

\section{The Background for the Classification of Consequences: The Legitimate Types of Logical Reasons}

\subsection{Division of Logical Reasons}

Sa skya Pandita discusses the types of logical reasons in the tenth chapter of the Rigs gter, on inference-for-oneself. His division, like that of his predecessors, elaborates on Dharmakīrti's threefold division of logical reasons qua essential property (rang bzhin, Skt. svabhāva), effect ('bras bu, Skt. kārya), and non-apprehension (mi dmigs pa, Skt. anupalabdhi). ${ }^{6}$

\subsubsection{Subdivisions of Essential Property and Effect}

For logical reasons qua essential property and effect, Sa skya Pandita distinguishes between the genuine ones (rtags dngos) and those that are subsumed under them (khongs su 'du ba). Two cases are subsumed under the category of essential property: the "complete causal complex" (rgyu tshogs pa tshang ba) posited to infer the fitness for the arising of an effect and the "capable unimpeded cause" (rgyu nus pa thogs med) posited to infer the effect (Rigs gter X, 340,9-341,13). One case is subsumed under the category of effect: that in which the logical reason and the property to be proven are distinct entities that are not directly causally related, as for instance when inferring the presence of water from a waterfowl (Rigs gter X, 341,14-343,4).

\subsubsection{Subdivisions of Non-apprehension}

Non-apprehension is divided into non-apprehension properly speaking ( $m i$ dmigs $p a$ _- of which four subtypes are distinguished-and apprehension of something incompatible ('gal ba dmigs pa). Two types of incompatibility are distinguished:

\footnotetext{
6 This threefold division is first stated in Rigs gter X, 335,11-13 as a "division [of logical reasons] based on the [formulation of the] argument" (sbyor ba'i sgo nas dbye ba). The three are then dealt with in detail in the section "elucidating their nature" (de'i rang bzhin nges par bya ba), Rigs gter X, 336,2-343,4. In comparison, see Phya pa's division, discussed in Hugon (2016b, pp. 889-896).
} 
factual incompatibility (lhan cig mi gnas 'gal) and conceptual incompatibility (phan tshun spangs 'gal).

\section{a. Factual Incompatibility}

For the types of apprehension of something incompatible involving factual incompatibility, Sa skya Pandita follows the line of Jitāri's twelve-fold division, which was already adopted by Phya pa (see Hugon 2016b, §1.2). He likewise illustrates the twelve subtypes with arguments relying on the incompatibility between elements of a "heat group" (fire itself; a subtype of fire, such as sandalwood fire; smoke, the effect of fire; the capable unimpeded cause of fire) and elements of a "cold group" (cold itself; a subtype of cold, such as hoarfrost; hair-raising, the effect of cold; the capable unimpeded cause of cold). This four-by-four configuration, according to Jitāir, only defines twelve types of apprehension of something incompatible, not sixteen, because the "capable unimpeded cause" is not recognized as a legitimate distinct reason to negate elements of the other group. ${ }^{7} \mathrm{Sa}$ skya Pandita agrees with Jitāri and criticizes scholars who consider it to be a distinct type of apprehension of something incompatible and thereby arrive at a count of sixteen subtypes. $^{8}$

\section{b. Conceptual Incompatibility}

Properties that are directly incompatible (phan tshun spangs 'gal dngos)—like "permanent" and "impermanent"-cannot be adduced as logical reasons for negating each other (Rigs gter X, 338,4-8). However, in cases in which direct incompatibility is indirectly involved in the opposition between two properties, one of them can be adduced as logical reason qua "apprehension of something incompatible" to negate the other. For such cases, Sa skya Paṇita first mentions an opposition he describes as "characterized by this (i.e., by direct conceptual incompatibility)" (de yis(/yi) khyad par byas pa). An instance of this is the opposition between "produced" (byas pa) and "permanent entity" (rtag pa'i dngos $p o$ ), because it relies on the direct conceptual incompatibility $(\rightarrow \leftarrow)$ between "produced" and "non-produced," the latter being the pervader of $(\mathrm{n})$ "permanent entity."

\begin{tabular}{rl|}
\hline Produced $\rightarrow \leftarrow$ & Non-produced \\
& $\cap$ \\
& Permanent entity
\end{tabular}

When "produced" is adduced as a logical reason to negate "permanent entity" (or, in other words, to affirm the "voidness of permanent entity"), its type is accordingly defined as the "apprehension of something incompatible with the pervader [of the negandum]" (khyab byed 'gal ba dmigs pa).

\footnotetext{
7 See Hugon (2016b, $\$ 1.3$ and 893, Table 2). For more details on the "capable unimpeded cause," see ibid., pp. 895-896.

8 Rigs gter X, 337,2-338,3. The sixteenfold model criticized here corresponds to the one adopted by gTsang nag pa and mTshur ston (Hugon 2016b, pp. 901 and 902, n. 37).
} 
Sa skya Pandita then proceeds to say that those cases in which the incompatibility amounts to, or involves, an invalidation by a valid cognition (tshad mas gnod pa' $i$ ' $\mathrm{gal} \mathrm{ba)^{9 }}$ are subsumed under such a type as well. That is to say, the logical reason is of the type "apprehension of something incompatible with the pervader [of the negandum]" (khyab byed 'gal ba dmigs pa, Skt. vyāpakaviruddhopalabdhi). However, in his autocommentary, Sa skya Pandita states that the type of the logical reason is subsumed under the "apprehension of something pervaded by something incompatible [with the negandum]" ('gal khyab dmigs pa [short for: 'gal bas/ba'i khyab bya/pa dmigs pa], Skt. viruddhavyāptopalabdhi), and he describes in such a way the relation between the logical reason and the negandum in two examples: in the first, the property "contingent/dependent" (ltos pa or ltos bcas, Skt. apekșā, sāpekșatva, āyattatā), or more specifically, "dependent on other causes" (rgyu gzhan la ltos pa), is posited to negate "necessary" (nges pa, Skt. avaśya[tva]); in the second, the property "non-contingent" (ltos med) is posited to negate "nonnecessary" (ma nges pa). ${ }^{10}$

It is peculiar that the autocommentary repeats the term "subsumed" ( $d u$ ) found in the verse (in its past form, 'dus) but also modifies the identification of the type under which this case is subsumed. However, the two alternative characterizations of the logical reason in the examples remain understandable. Indeed, as illustrated for the first example in the diagram below, the property "contingent" can be described

(1) either as something that is directly incompatible with "non-contingent," "noncontingent" being the pervader of $(\Pi)$ the negandum "necessary" (this is the same relation as that between "produced" and "permanent entity"),

(2) or as something pervaded by (U) "non-necessary," "non-necessary" being directly incompatible with the negandum "necessary" (this is how it is explained in the autocommentary).

\footnotetext{
9 On the Dharmakīrtian background of this sort of incompatibility, see Kellner (1997, p. 503). Kellner suggest that the appellation "invalidation via a valid cognition" refers to the inference in which one of the two incompatible properties negates the other. Note that in the case of Sa skya Pandita, the previous case involving "characterization by direct incompatibility" is also discussed in the autocommentary in terms of an inference in which one property negates the other. The specificity of the present case thus remains unclear. One possibility (but this remains speculative) is that the "invalidation" does not refer to the negation of one property via the other, but to the fact that the inference based on this incompatibility grounds an invalidation, namely, the invalidation of the presence of a property in a locus; in other words, it establishes the negative entailment for another proof.
}

${ }^{10}$ Rigs gter X, 338,13-339,2 (Rigs gter dpe bsdur ma 2 345,9-18): tshad mas gnod pa'i 'gal ba yang \| khyab byed 'gal ba dmigs par 'dus || tshad mas gnod pa'i 'gal ba ltos pas nges pa 'gog pa dang|ltos med kyis* ma nges pa 'gog pa lta bu** ste dper na gang ltos pa dang bcas pa de ma nges pa yin te gos la tshon bzhin | 'jig pa'ang rgyu gzhan la ltos so zhes bya ba lta bu nges pa dang 'gal ba ma nges pa'i khyab bya*** ltos bcas bkod nas nges pa 'gog pa'o $\|$ [...] 'gal khyab dmigs par 'du'o $\|$.

* kyis RT4 (230a3), em. dpe bsdur ma 2 : kyi dpe bsdur ma 1 (on the versions referred to here and below, see Sect. 2.2).

** Instead of ltos med kyis ma nges pa 'gog pa lta bu, RT3ii (144b2) and RT5 (219b4) read: nges pas ltos pa 'gog pa lta bu (but the second example is explained later like in the other versions).

*** The editors of the Rigs gter dpe bsdur ma 1 give the variant "byed" without indication of its source. This is also the (mistaken) reading of RT5 (219b5). RT3ii (144b4) and RT4 (230a5) have the reading "bya." Rigs gter dpe bsdur ma 2 does not give any variant.

On the notions of contingency and necessity and their role in Dharmakīti's proof of momentariness, see Sakai (2018). 


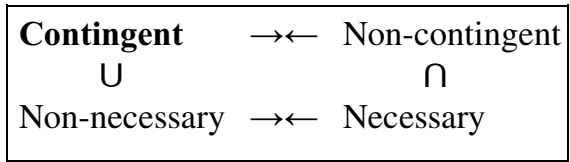

The same can be said, mutatis mutandis, of the property "non-contingent" in the second example. The possibility of this dual identification in cases where the direct incompatibility is conceptual (but not in cases involving factual incompatibility) will play a role below when arguments by consequence and their reverse form will be considered. Indeed, if the logical reason $(P)$ and the negandum (not- $Q$ ) of a consequence stand in a relation such as the one between "contingent" and "necessary," in the reverse form, the logical reason (not- $Q$ ) and the negandum $(P)$ likewise stand in the same relation. Thus, both the logical reason of the consequence $(P)$ and that of the reverse form (not- $Q$ ) can be said to be of either type.

\subsubsection{The Number of Legitimate Types}

Sa skya Pandita does not provide us with a summarized count of the legitimate types of logical reasons. Thus, various numbers can be arrived at depending on what exactly is counted as a "type."

- If the distinct expressions used for the types of logical reasons that are deemed legitimate are counted, one arrives at eighteen types (the very same eighteen types that Phya pa took as the basis for his division of consequences, see Hugon (2016b, §1 and Table 1) as well as Table 1).

- If the various cases that are discussed are counted, one arrives at a larger number. Sa skya Pandita indeed mentions three cases of essential property (one genuine and two that are subsumed under the genuine case) and two cases of effect (one genuine and one that is subsumed under it). He further distinguishes cases of "apprehension of something incompatible" involving factual incompatibility and cases involving conceptual incompatibility; and in his discussion of the latter, he mentions two cases: one involving characterization by direct conceptual incompatibility and another involving invalidation by a valid cognition (for which two alternative types are given). When discussing the total number of legitimate types to be taken as the basis for classifying consequences, commentators commonly disregard the distinctions pertaining to reasons qua effect and essential property. The total number they consider varies depending on whether some or all the cases involving conceptual incompatibility are counted separately. ${ }^{11}$

\footnotetext{
11 Śākya mchog ldan thus states in his Pham byed that Sa skya Paṇita accepts twenty legitimate types (the two subcases of apprehension of something conceptually incompatible counting as distinct types), although, in term of distinct expressions, they are reduced to 18. Pham byed 186b1-4: 'jam dbyangs chos kyi rjes | gtan (186b2) tshigs yang dag thams cad nyi shur bsdu ba mdzad de | [...] nyi shu po de'ang (186b4) ming ris kyi sgo nas ni bco brgyad kho nar 'dus pa yin te | phan tshun spangs 'gal la brten pa gnyis po la $\mid$ snga ma gzhan du ma 'dus pa'i ming ris zur pa med pa'i phyir $\mid$. But in his Rol mtsho (145b14) he counts nineteen types, as he counts as one distinct type (instead of two) the apprehension of something incompatible involving conceptual incompatibility.
} 


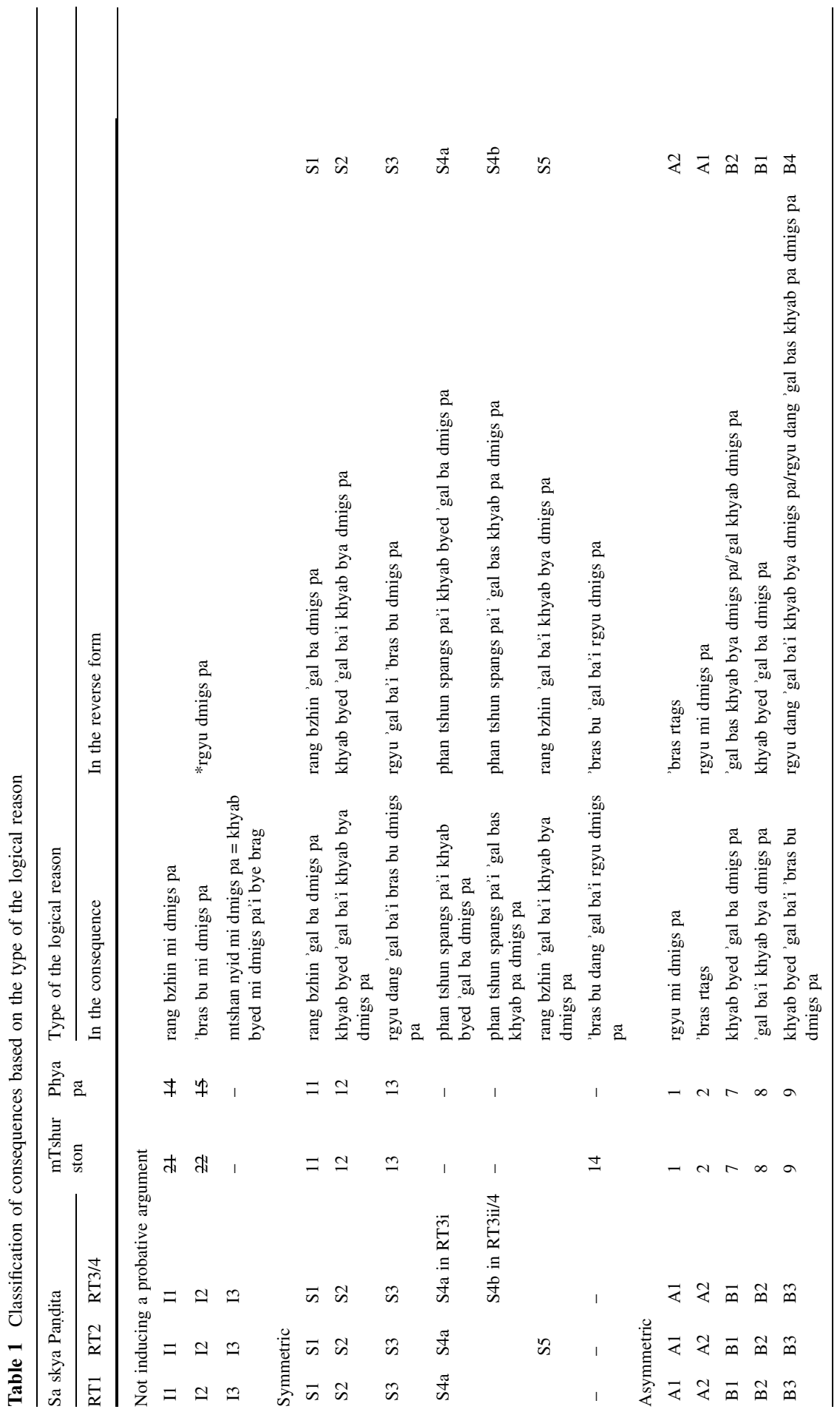




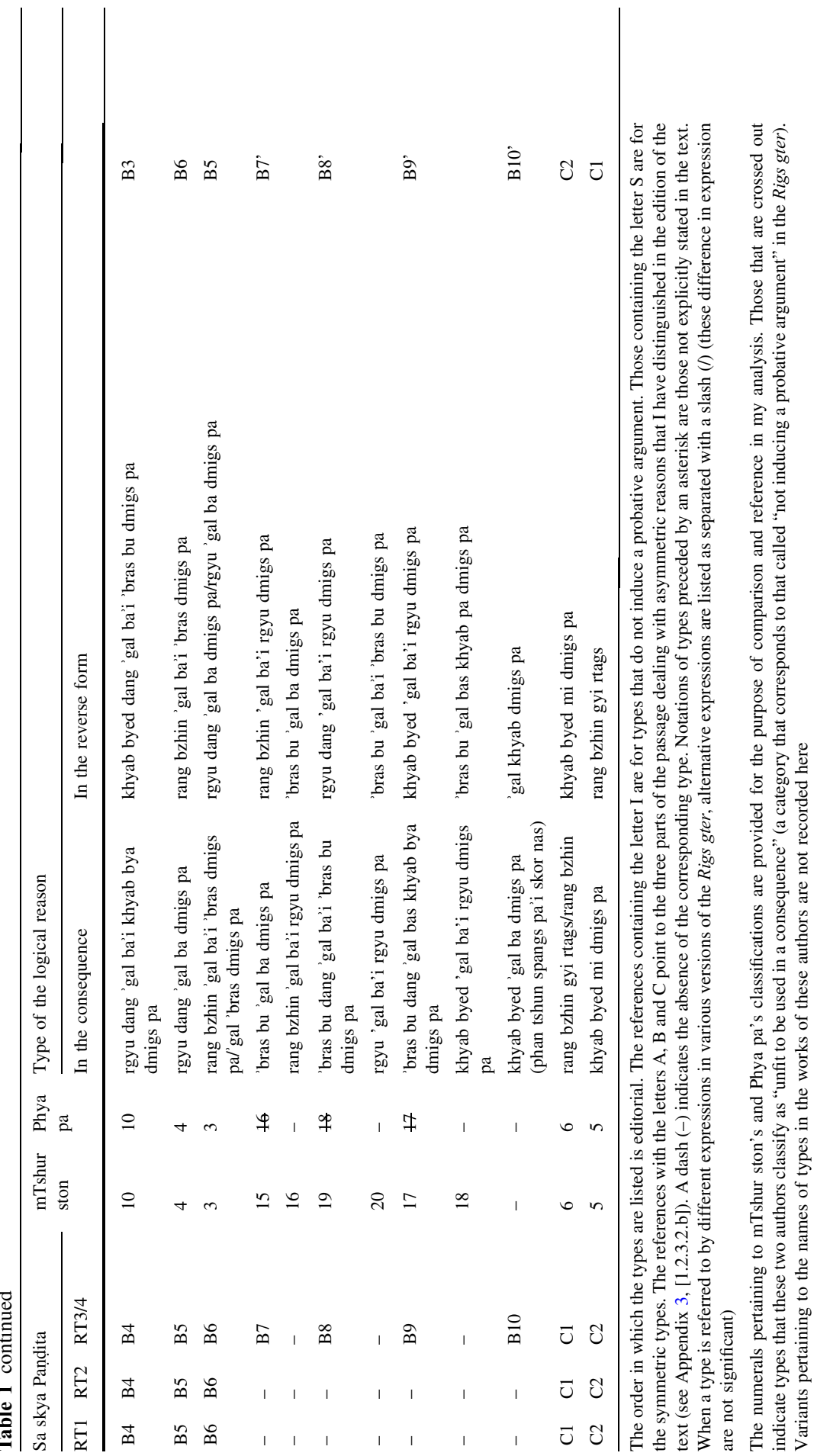




\section{Sa skya Paṇdita's Classification of Arguments by Consequence Based on the Type of the Logical Reason}

\subsection{The "Logical Scenario"}

Based on Sa skya Pandita's discussion in the chapter of the Rigs gter on inferencefor-oneself and the associated possible counts of legitimate types, when it comes to the division of consequences based on the type of the logical reason, the "logical scenario" that suggests itself could be either a classification identical to that of Phya pa (indeed, both authors perfectly agree on the 18 legitimate types referred to by distinct expressions), or a slightly modified classification in which some or all subcases-in particular cases of non-apprehension involving conceptual incompatibility — would be considered separately.

For the sake of internal consistency within the Rigs gter, the "logical scenario" presupposes that if the logical reason of the reverse form is a non-legitimate type, the consequence cannot be classified as "inducing a probative argument" (sgrub byed 'phen $p a$ ), since the reverse form would not be a correct direct proof.

If the list of legitimate types serves as the basis for the division of consequences (as it does in the classification of Sa skya Pandita's predecessors), it is also to be expected that non-legitimate types would not be considered in this classification, even if the type of the logical reason in the hypothetical reverse form were to be itself legitimate.

\subsection{The Versions of the Rigs gter Taken into Consideration in the Present Study}

Although I could not consult all the extant versions and there are further prints and manuscripts of the texts that are no longer accessible (or are waiting to be discovered), ${ }^{12}$ the sample I have taken into consideration here represents the most important recensions, i.e., those that appear to have had the largest impact and distribution and were taken as a basis by the commentators (more on this in Sect. 3).

\footnotetext{
12 See Jackson (1983), van der Kuijp (1984, 1993b). Several manuscripts of the Rigs gter are listed in the 'Bras spungs dkar chag (see Nos. 016331, 016336, 016401, 016406, 016444, 016465), but given the number of folios, they probably contain only the verses. Only two entries (No. 016391, rdo dpar, 190 folios, and No. 016399, shing dpar, 190 folios) indicate a version of the text with the autocommentary (see n. 15).

The editors of Rigs gter dpe bsdur ma 1 mention (Introduction, p. 4) that they consulted a "Glang thang print" (glang thang dpar ma) from the 15th century and a non-identified manuscript in cursive script, the text of which was quasi-identical to RT3i (on which see below). The "Glang thang print" must be the Glang ri thang monastery blockprint ordered by Kun dga' rgyal mtshan dpal bzang po, that was completed in 1445. It is housed in the Tibetan library of the Cultural Palace of Nationalities, catalogue No. 004782 (2). See van der Kuijp (1993a, p. 285 and n. 17).

van der Kuijp (1993a, p. 285) mentions a print prepared in Thub chen mngon par dg[y]es pa temple in Glo bo smon thang in 1474, which was known to Śākya mchog ldan.
} 


\section{RT1-The sDe dge Print}

Although this edition is an 18th-century compilation, ${ }^{13}$ the passage under consideration in this version appears to match the model of classification known to thirteenth-century scholars (e.g., lHo pa kun mkhyen, see Sect. 3), and Śākya mchog ldan's 15th-century discussion of this passage attests that he knew a version akin to RT1. Note that the sDe dge version of the verses only (which I refer to as $\mathbf{R T 1}_{\mathbf{v}}$ ) contains a different reading in one of the verses than the version with autocomentary.

\section{RT2-The Zhwa lu Manuscript (Late Fourteenth Century) ${ }^{14}$}

I could only access this version through the variants indicated in the 2005 and 2007 comparative recensions of the Rigs gter (cf. Rigs gter dpe bsdur ma 1 and Rigs gter dpe bsdur ma 2 in the bibliography). The two comparative recensions differ on some occasions in their recording of the variants of RT2 and it is not always clear whether the variants of RT2 are additions or alternative readings (see the notes to the edition in Appendix 3). The editors of Rigs gter dpe bsdur ma 2 also indicate variants pertaining to the version of the text with the verses only $\left(\mathbf{R T} \mathbf{2}_{\mathbf{v}}\right)$. They further record interlinear notes on the manuscript that, for instance, identify the proponents of the views discussed in the Rigs gter (no such note is found in the passage under consideration).

\section{RT3-The Two Mongol Prints (hor par ma) (Late Thirteenth Century)}

Two xylographs of the Mongol printed edition of the Rigs gter are preserved at the Tibetan library of the Cultural Palace of Nationalities in Beijing (van der Kuijp 1993a). Van der Kuijp dates the first (Tibetan library catalogue No. 004817) to the beginning of the Yuan dynasty, the other (Tibetan library catalogue No. 004796) to the middle period of this dynasty, i.e., 1284 and 1315 (or 1339) respectively (ibid.: 280-283). See also Jackson (1987, p. 73).

RT3i-The Mongol print that van der Kuijp takes to be the oldest (No. 004817) appears to be the source used in the comparative recensions. ${ }^{15}$

\footnotetext{
13 The reproduction dates the sDe dge edition to 1736. The question of the sources used by the editors of the sDe dge print of the Sa skya bka' 'bum is addressed in Jackson (1983). See also the list provided in van der Kuijp (1984, p. 40).

14 According to the editors of the Rigs gter dpe bsdur ma 1 (Introduction, p. 4), the Zhwa lu manuscript dates to the second part of the fourteenth century and thus the time of Rin chen rnam rgyal (1318-1388), who became the abbot of Zhwa lu in 1356 (zha lu' $i$ dpe rnying 'di ni dus rabs bcu bzhi pa'i smad tsam la sgra tshad pa rin chen rnam rgyal gyi sku dus su bris pa zhig yin par mngon).

15 The editors of Rigs gter dpe bsdur ma 1 note that they have relied on the print preserved in the 'Bras spungs library bearing the reference Zha 25 (Introduction, p. 4,17-20). This corresponds to the item bearing the No. 016391 in the 'Bras spungs dkar chag. Note that the 'Bras spungs dkar chag gives the size " $65.6 \times 12.4 \mathrm{~cm}$ " for this item. Van der Kuijp (1993a, pp. 291-292) gives the measure " $64 \times 12.5$ " for the first print (No. 004817) and "65.2×12.5" for the second (No. 004796).

The editors mention in their introduction an element found in the colophon of the first Mongol print discussed by van der Kuijp (No. 004817) (namely, that 200 copies of this text were commissioned by 'Bol gan) but take the "wood-male-monkey year" in the colophon to represent 1344 rather than 1284. This would indicate that their source is this first Mongol print.

The editors of Rigs gter dpe bsdur ma 2 do not indicate what their source for the readings they mark with the sigla "ho" is. In view of the variants that they indicate, they rely on the same source as the editors of Rigs gter dpe bsdur ma 1.
} 
RT3ii-For the Mongol print bearing the Tibetan library catalogue No. 004796, I relied on the scans accessible via the Buddhist Digital Resource Center (formerly TBRC). ${ }^{16}$

\section{RT4-The Golden Manuscript of Glo bo sMon thang (15th)}

This early (fifteenth or sixteenth centuries) 301-folio manuscript originates from Lo Mustang (glo bo smon thang) (see Jackson 1987, pp. 237 and 517; 1991b, pp. 3 and 30). It was part of a manuscript of the Sa skya bka' bum (vol. 17, no. 5) (Jackson $1991 b$, p. 32). The original is written in light letters on dark black paper. In spite of its title (Tshad ma rigs gter gyi rtsa ba dang rang 'grel), it contains only the autocommentary. For the reading of this version I rely on a black-and-white reprint by the Sa skya Center.

\section{RT5-The Thub bstan lha chen Edition}

This is a xylographic 282-folio edition of the autocommentary. Its colophon ${ }^{17}$ specifies that the blocks are kept at the "Great Seminary of Thub bstan lha chen" (282a6). The establishment of a chos grwa chen po thub bstan lha chen is ascribed to sNgags 'chang Ngag dbang Kun dga' rin chen (1517-1584), the 23rd throne-holder (khri 'dzin) of Sa skya (cf. TBRC, Resource ID P460), which, provided it corresponds to the place mentioned in the colophon, gives a terminus a quo for dating this edition. The donator is identified in the colophon as Tshong dpon nyi rgyal.

Jackson (1991a, p. 104) mentions the presence of an exemplar of this text (which he refers to as the "Sa skya edition") at the Bihar Research Society in Patna (No. 1503). Another exemplar preserved in Tyangpoche was filmed by the NepalGerman Manuscript Preservation Project (ref. No. 15252, reel no. L179/10) (Hugon 2008, p. 365).

An interesting feature of this edition is the presence of notes that appear in a smaller size than the main text, to which they are linked by dotted lines.

When dealing with RT5 in my study of chapters four and ten of the Rigs gter (cf. Hugon 2008, vol. 2), I noted that it frequently sided with RT1 against RT3ii/RT4; but there are also many cases of RT5 siding with RT3ii/RT4 against RT1. The dpe bsdur ma editions make it possible to establish that RT5 occasionally shares a reading specific to RT2, although it hardly systematically sides with RT2 against RT1 or against RT3i/RT4. ${ }^{18}$

\footnotetext{
16 The TBRC copy bears the catalogue number 004796 on the first folio and clearly corresponds to the second print discussed by van der Kuijp.

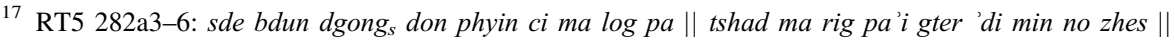

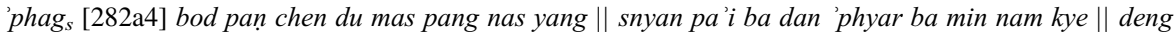
dus blun po'i btsan gtam tshad mar 'dzin || gzhung lugs 'di 'dra bshad tshe chos log mngon \| rgyu des 'jig rten khams [282a5] 'dir mi 'dod pa \|| rnam mang byung la shes ldan su mi sems || chos spyin bdag po tshong dpon nyi rgyal gyis || 'di mtshon dus gsum dge tshogs gcig $b^{*} m s$ mthus || lung rtogs bstan 'dzin [282a6] [bshad sgrub mtsho] ltar 'phel || 'jig rten bde dga' dpal la spyod par shog || sarba manga lam \| par 'di chos gra chen po thub bstan l[h]a chen nang bzhugs so I.

${ }^{18}$ For instance, RT5 reflects the specific reading of RT2 in Rigs gter dpe bsdur ma 196,$17 ; 98,18$. But the reading of RT5 does not match the first variant of RT2 indicated in Rigs gter dpe bsdur ma 1 for the beginning of the text $(44,11 ; 50,1 ; 53,7 ; 54,2)$. Of the six variants in RT2 indicated in Rigs gter dpe bsdur ma 164 , it only matches one $(64,11)$.
} 
In the passage under consideration in this paper, an interesting phenomenon can be observed: the editor of RT5 was obviously aware of a reading such as the one attested in RT2 and of that attested in RT3ii. However, instead of electing one of them, he provides both versions in succession, at least for the passage on asymmetric types (see Appendix 3, [1.2.3.2.b]). For the end of the preceding passage on symmetric types, [1.2.3.2.a], the reading of RT5 corresponds exactly to that of RT3ii/RT4 at the exception of one faulty reading. Following that, one finds the text of section [1.2.3.2.b] in a version that also corresponds to that of RT3ii/RT4, followed by a repetition of the same section (with the omission of the beginning, since the passage starts in mid-sentence), this time in a version that corresponds to RT2. I refer to the former passage as RT5.1, to the latter as RT5.2.

Unfortunately, two crucial folios $(277 \mathrm{~b}, 278 \mathrm{a})$ are missing in the copy of RT5 available through the Nepal-German Manuscript Preservation Project. ${ }^{19}$ Folio 277a ends on the third example of a type that does not induce a probative argument (I3, cf. Appendix 3 [1.2.3.1]) and folio 279a starts with the end of the section on symmetric types. Since only a few sentences separate these two passages in the other versions, I suspect that the missing folios give the reading of two versions for symmetric reasons and possibly additional material pertaining to the section on the types that do not induce a probative argument.

\section{RT6-The Lu phu Manuscript}

The variant readings of this manuscript, which is part of a compilation of the works of the five great Sa skya pa masters preserved at Lu phu monastery, are recorded in Rigs gter dpe bsdur ma 2.

As may be observed in the edition of the passage (Appendix 3), the sources I have consulted are representative of three main models with regard to the classification that is proposed. These models are found, respectively, in RT1, RT2, and RT3/4.

RT1 and RT2 concord to a large extent against RT3i, RT3ii and RT4, but RT1 and RT2 sometimes also differ from one another, especially in [1.2.3.2.a] and in Part B of [1.2.3.2.b].

In the passage under consideration, the reading of RT4 is rigourously identical to that of RT3ii. The only exceptions are cases where RT4 has a faulty reading. ${ }^{20}$ Based on the dpe bsdur ma editions, it would appear that RT3i and RT3ii are not identical: RT3i frequently sides with RT1 whereas RT3ii has a different reading. ${ }^{21}$ But the two versions present the same model of classification of consequences.

\footnotetext{
19 It has been brought to my knowledge by the NGMPP resident representative, Dr. Hanisch, that the monastery of Tyangpoche, where this print was kept, suffered damage from a fire in 1989 (email communication, 27.10.2013). There remains some hope of retrieving the corresponding passages from the exemplar kept at the Bihar Research Society in Patna.

20 The same was observed for the tenth chapter of the Rigs gter (Hugon 2008, p. 365).

21 Note that most of the differences between RT3i and RT3ii are cases where the comparative editions do not indicate a reading for RT3i distinct from that of RT1. One may therefore suspect that the editors omitted to report a variant in RT3i matching the reading of RT3ii. One case that seems to support the idea that the two editions are indeed different is the reading of RT3i indicated at the end of [1.2.3.2.a]. The editors of Rigs gter dpe bsdur ma 2 explicitely indicate that the variant in RT3i pertains only to the last part of the sentence, whereas RT3ii differs from RT1 in the first part of the sentence already.
} 
RT5 does not propose a distinct model of classification of consequences, but presents both that found in RT2 and that found in RT3/4.

Thorought the text, RT6 appears to share the readings of RT2 that differ from RT1 in a large proportion. In the passage under consideration RT6 presents in Part B a version that combines elements from RT1/2 with elements from RT3/4. It fails, however, to arrive thereby at a coherent logical scenario, and does not seem to represent a version known to the Tibetan commentators. I have included the variants of RT6 in the edition of the passage, but do not discuss the mixed model it proposes in my analysis.

\subsection{Diverging Classifications of Consequences}

To facilitate the following discussion, I will refer below to the various types by the specific notations given in Table 1.

\subsubsection{Types that do not Induce a Probative Argument}

All versions concur in counting, naming and illustrating three types of logical reasons that do not induce a probative argument: I1, I2 and I3. The variants in this section are insignificant (orthographic differences and scribal mistakes, especially in RT4), with one exception, which however does not imply a change in meaning. ${ }^{22}$

Types I1 (non-apprehension of the nature) and I2 (non-apprehension of the effect) were already included in the corresponding category of logical reasons termed "unfit to be used in consequences" by Phya pa (Nos. 14, 15), gTsang nag pa and mTshur ston (Nos. 21, 22) (see Hugon 2016b, §1.6), but the third, I3, is an innovation. Exemplified by the argument "Because something does not have a hump and a dewlap, it follows that it is not a cow," it is referred to as the "nonapprehension of the definiens" (mtshan nyid mi dmigs pa) in the verse and as a "specific sort of non-apprehension of the pervader" (khyab byed mi dmigs pa'i bye brag) in the autocommentary. One must understand here that "hump and dewlap" (the accepted definiens of cow) can alternatively be characterized as a definiens or as the pervader of the definiendum "cow." In the latter case, its non-apprehension constitutes a "specific sort of non-apprehension of the pervader," because the standard case of non-apprehension of the pervader is permitted in consequences and induces a probative argument (this is type C2). The non-apprehension of the definiens is not mentioned in the tenth chapter of the Rigs gter, either as a distinct type of reason or, as suggested here in the autocommentary, as a subtype of non-

\footnotetext{
${ }^{22}$ When explaining why type I1 does not induce a probative argument, one of the arguments is stated in terms of shes 'dod med ("absence of desire to know") in RT2, RT3ii, RT4 and RT6, while RT1/RT3i read phyogs chos med ("absence of qualification of the subject"). Both readings have the same import, insofar as the "absence of desire to know" entails the non-establishment of the feature of the "qualification of the subject." The parallel versions of the argument in gTsang nag pa's bsDus pa (162b5) and in mTshur ston's sGron ma (65b8) both invoke the absence of desire to know, whereas Phya pa spoke of grub pa la sgrub ("the probandum being already proven").
} 
apprehension of the pervader. This raises the question whether there are in fact three distinct types in this category, or only two, or two and a half. ${ }^{23}$

While Phya pa and mTshur ston did not consider a type akin to I3 in their classification of logical reasons and in their classification of consequences (although they discuss elsewhere inferences relying on the relation between definiens and definiendum), ${ }^{24}$ a logical reason of this type is found in the classification of consequences in an epistemological treatise of the thirteenth-century gSang phu scholar Chu mig pa seng ge dpal. ${ }^{25}$ For reasons that I will not develop here, I am of the opinion that this reflects the influence of Sa skya Pandita on Chu mig pa, rather than hinting at the existence of a model followed by both these scholars.

Phya pa included three other types in this category (see Phya pa's Nos. 16, 17, $18),{ }^{26}$ cases that induce a reverse form whose logical reason consists in some variety of "apprehension of the cause" ( rgyu dmigs pa), a short expression for the "apprehension of the capable unimpeded cause." Phya pa, following Jitāri, does not accept the "apprehension of the capable unimpeded cause" to be a legitimate logical reason among reasons qua apprehension of something incompatible. mTshur ston, on the other hand, holds such a type to be legitimate. He thus includes in the category "fit to be used in an inference" both the varieties of apprehension of the cause (mTshur ston's Nos. 14, 16, 18, 20) and the reasons inducing a reverse form involving the "apprehension of the cause" (mTshur ston's Nos. 14, 15, 17, 19). Given that Sa skya Pandita, like Phya pa, does not accept the "apprehension of the cause" as a legitimate subtype of apprehension of something incompatible (see Section 1.1.2), one could expect that B7, B8 and B9 (= Phya pa's Nos. 15, 19, 17) would likewise be found in the category "not inducing a probative argument," but RT1 and RT2 simply omit discussing these three types, whereas RT3/RT4 locates them among asymmetric reasons.

\subsubsection{Symmetric types}

Turning to types that induce a probative argument, Sa skya Pạdita starts with symmetric types.

The first three cases listed in the autocommentary-S1, S2, S3 - are the same in all versions and are illustrated with the same examples (logical reasons from the "cold group" negating elements from the "heat group"), although the phrasing

\footnotetext{
23 Śākya mchog ldan considers that I3 amounts to the "non-apprehension of the nature" (I1). See Rol mtsho 144b6-145a1 (cf. Onoda 1986, p. 78) and Pham byed 183a2ff. Go rams pa explains I3 and C2 as two varieties of a single type (cf. Onoda 1986, p. 77).

24 For a discussion of proofs positing the negation of a definiens to negate a definiendum, see, for instance, Mun sel 81b6-7.

${ }^{25}$ Chu mig pa distinguishes two kinds of non-apprehension of the pervader, according to whether the logical reason consists in the negation of the definiens or in the negation of something else ( $r$ Nam rgyal 65a8-b1). The first is illustrated by the same example that Sa skya Pandita gives for I3. Chu mig pa's argument to reject this type of logical reason from the range of consequences is that the reverse form would be the proof of a definiens based on a logical reason qua definiendum, which is not acceptable.

26 These types are listed in the table under the heading "asymmetric," as this is how the versions of the Rigs gter that deal with these types classify them (see below).
} 
differs for the last two in RT3ii/RT4/RT5. They correspond to the three symmetric types already distinguished by Phya pa (cf. Phya pa's Nos. 11, 12, 13), to which mTshur ston adds a fourth type (mTshur ston's No. 14). ${ }^{27}$

The fourth symmetric type (S4) is illustrated in all versions by the logical reason "contingent" negating "necessary." As discussed in Section 1.1.2.b, in the tenth chapter Sa skya Pandita identifies the relation of this logical reason to the negandum in two ways:

- as the "apprehension of something incompatible with the pervader [of the negandum]" (khyab byed 'gal ba dmigs pa) (S4a) and

- as the "apprehension of something pervaded by something incompatible [with the negandum]" ('gal ba'i khyab bya dmigs pa) (S4b).

These two types induce each other (like B1 and B2 in the case involving factual incompatibility). So, strictly speaking, S4a induce S4b; but since the logical reason of the reverse form can likewise be characterized as $\mathrm{S} 4 \mathrm{a}$, it is also possible to say that S4a induces S4a. The same applies to S4b. Thus, both S4a and S4b can be conceived of as "symmetric." However, none of the versions of the Rigs gter list both S4a and S4b in this category. They all give a single example ("contingent" negating "necessary") and link it with a single type: the type is identified as S4a in RT1/RT2/RT3i/RT6, and as S4b in RT3ii/RT4/RT5. This could indicate that what is at stake is just to distinguish the type of conceptual incompatibility that involves invalidation by a valid cognition, and that this can be done indifferently by listing $\mathrm{S} 4 \mathrm{a}$ or S4b, since these two are alternative characterizations of logical reasons of such a type.

Given the logical reason "contingent" in a consequence negating "necessary," the reverse form should feature the logical reason "necessary" negating "contingent." This is spelled out correctly in RT1/RT2/RT6, but RT3i/RT3ii/RT4/RT5 mistakenly give, for the reverse form, the logical reason "non-contingent" negating" "nonnecessary." The logical reason "non-contingent" is the second example that Sa skya Pandita presents in the tenth chapter along with the logical reason "contingent," and it has the same features as the latter, which might explain the confusion.

In RT2 (and RT6), an additional fifth case (S5) is found between S1 and $S 2^{28}$ : the "apprehension of what is pervaded by something incompatible with the nature [of the negandum]" (rang bzhin 'gal ba'i khyab bya dmigs pa) (S5). The consequence is illustrated by the logical reason "cold" negating "sandalwood fire" (grang reg yod pa'i phyir tsandan gyi me med par thal) and the reverse form by the logical reason "sandalwood fire" negating "cold" (tsandan gyi me yod pa'i phyir grang reg med).

\footnotetext{
27 See Hugon $(2016 \mathrm{~b}, \S 1.4)$. mTshur ston adds the "apprehension of the cause of something incompatible with the effect [of the negandum]" (see Appendix 2, §10), exemplified by the apprehension of the capable unimpeded cause of cold negating the capable unimpeded cause of fire, which Sa skya Paṇita (like Phya pa) does not accept to be a legitimate type.

28 Rigs gter dpe bsdur ma 1 does not indicate clearly whether S5 is added after S1 or replaces S1 and the notation in Rigs gter dpe bsdur ma 2 is problematic (see note ${ }^{\beta}$ in [1.2.3.2.a]). But given the reading of the verse in RT2 $2_{\mathrm{v}}$ there is little doubt that RT2 lists S5 as one of five symmetric types. In the commentary of rGyal tshab Dar ma rin chen (1364-1432), which relies on a version that corresponds to RT2 (see Sect. 3), S5 is listed as a fifth case after S1-S4a, which rGyal tshab then proceeds to criticize (cf. Rigs gter rnam bshad 145a6-b1).
} 
As noted by several commentators, this reading presents two problems:

One problem is that the "apprehension of what is pervaded by something incompatible with the nature [of the negandum]" is not a symmetric type when it involves factual incompatibility (cf. B2), but only when it involves conceptual incompatibility (cf. S4b). ${ }^{29}$

Another problem is that the "apprehension of what is pervaded by something incompatible with the nature [of the negandum]" is the type of the logical reason in the reverse form (i.e., the type of the logical reason "sandalwood fire" negating "cold"), not that of the logical reason "cold" negating "sandalwood fire" in the consequence. The latter is an "apprehension of something incompatible with the pervader [of the negandum]" (= B1, khyab byed 'gal ba dmigs pa). ${ }^{30}$

Thus, RT2 is not only logically mistaken, it is also internally inconsistent, because B1 and B2 are further listed in Part B as asymmetric. Note, however, that these types are then illustrated by the pair "fire"/"hoarfrost." The case of "sandalwood fire" negating "cold" found in RT1 as a second illustration of B2/ B1 in Part B is not listed in RT2.

\subsubsection{Asymmetric Types}

Part A, which lists A1 and A2 with an illustration of each and an explanation as to how these types induce each other, is identical in all versions (apart from minor differences and scribal mistakes). Part $\mathrm{C}$, which lists $\mathrm{C} 1$ and $\mathrm{C} 2$, is also the same in all versions, the only difference being in the way of formulating the illustration of these types in RT1/RT2 and RT3/RT4 respectively. It is in Part B, which deals with the subtypes of "apprehension of something incompatible" ('gal ba dmigs pa), that one finds more differences.

\section{RT1/RT2/RT5.2 Against RT3/RT4/RT5.1 on the Sorts of Incompatibility to be Considered}

A first difference between RT1/RT2 and RT3/RT4 stems from the fact that RT1/RT2 distinguish a single subtype involving conceptual incompatibility, which they classify among the symmetric types (cf. S4a). RT3/RT4 on the other hand distinguish two subtypes involving conceptual incompatibility. Based on their respective illustrations, it is clear that one of them (S4) relates to conceptual incompatibility involving invalidation by a valid cognition and the other (B10) relates to the case

\footnotetext{
${ }^{29}$ rGyal tshab notes that S5 is not symmetric and qualifies it as being an "invention by those who do not know the presentation of consequences" (Rigs gter rnam bshad 145b1-2: de rigs mthun 'phen pa la sbyor ba ni $\mid$ thal ba'i rnam bzhag mi shes pa kha cig gis rang bzo byas nas bcug par zad kyi). Glo bo mkhan chen also knew of this reading "in some texts" (gzhung kha cig las) and points to the lack of symmetry (Rigs gter nyi ma 255,24-25).

${ }^{30}$ Rong ston seems to have known a version akin to RT2 in which the type of the logical reason of the consequence in the fifth symmetric type is identified as khyab byed 'gal dmigs (Rigs gter nyi snying 360b6).
} 
involving "characterization by direct conceptual incompatibility." 31 (S4) is classified among symmetric types (cf. Sect. 2.3.2), but B10 is classified as asymmetric. This may be so because Sa skya Pandita offers only one way of characterizing the type of the logical reason in the latter case. The type of the reverse form of B10, the "apprehension of what is pervaded by something incompatible [with the negandum]" ('gal khyab dmigs pa, i.e., 'gal bas khyab bya dmigs pa or 'gal ba'i khyab bya dmigs $p a)$ (B10') - which is the counterpart of B2 in the case of conceptual incompatibility -is not counted as a distinct asymmetric type.

As a consequence of this difference, RT3/RT4 distinguish in Part B a list of types "from the group of incompatibility" ('gal ba'i skor nas), in which all the types are illustrated by cases involving factual incompatibility, and the single type B10 "from the group of mutual opposition" (phan tshun spangs pa'i skor). RT1/RT2 only list types from one group, which they respectively identify as the "group of the twelve apprehensions of something incompatible" ('gal dmigs bcu gnyis po 'i skor nas) (RT1) and the "group of incompatibility within the twelve apprehensions of something incompatible" ('gal dmigs bcu gnyis po la'ang 'gal ba'i skor nas) (RT2). ${ }^{32}$

\section{Divergent Lists of Illustrations for the Types in RT1/RT2/RT5.2 and in RT3/RT4/ RT5.1}

RT1/RT2 and RT3/RT4 differ as well regarding the illustration of the types they give in Part B. In addition, RT1 differs here from RT2.

RT1/RT2/RT5.2 start by listing three pairs of mutually opposing elements (the first from the "heat group" and the second from the "cold group"), each together with two types of logical reasons followed by the count "two."

\begin{tabular}{|llll|}
\hline fire & hoarfrost & B1 & B2 \\
smoke & hoarfrost & B3 & B4 \\
fire & hair-raising & B5 & B6 \\
\hline
\end{tabular}

This section which is literally identical to the corresponding paragraphs on asymmetric reasons in the sGron ma (see Appendix 2, §18-20) would have sufficed to cover the mention of all six types B1-B6. ${ }^{33}$ But instead of stopping here, all

\footnotetext{
31 B10-the "apprehension of something incompatible with the pervader [of the negandum]" (khyab byed 'gal ba dmigs pa)—is exemplified with the logical reason "produced" negating "permanent entity" (rtag dngos) (cf. Sect. 1.1.2.b). The reverse form is mistakenly illustrated with the logical reason "nonproduced" negating "impermanence" (ma byas pas mi rtag pa 'gog pa), whereas it should have featured the logical reason "permanent entity" negating "produced."

32 The expression "group of..." finds a precedent in mTshur ston's sGron ma. In the corresponding section, mTshur ston distinguishes among the apprehensions of something incompatible (of which he accepts sixteen types) between a "group of incompatibility" ('gal ba'i skor) (mTshur ston, Nos. 7-10, 34) and a "causal group" (rgyu skor) (mTshur ston, Nos. 15-20). The "group of incompatibility" only includes illustrations involving factual incompatibility (mTshur ston does not separately deal with those involving conceptual incompatibility in his classification of consequences). The "causal group" includes three types of reason involving the "apprehension of the cause" (rgyu dmigs pa) (mTshur ston, Nos. 16, $18,20)$ and three types of reason that induce a reason involving the latter (mTshur ston, Nos. 15, 17, 19).

33 For instance, B1 is the type of the logical reason "fire" negating "hoarfrost" in a consequence the reverse form of which would have a logical reason of type B2, and B2 is the type of the logical reason
} 
versions go on listing additional cases of the same types. Here, RT1 differs from RT2/RT5.2.

RT1 lists three pairs of elements (the first from the "heat group" and the second from the "cold group"), each pair together with two types of logical reasons followed by the count "two."

\begin{tabular}{|llll|}
\hline smoke & cold & B6 & B5 \\
sandalwood fire & cold & B2 & B1 \\
sandalwood fire & hair-raising & B4 & B3
\end{tabular}

Thereby each of the six types B1-B6 is illustrated twice, once by a logical reason from the "heat group" and once by a logical reason from the "cold group."

RT2/RT5.2 spell out two consequences with their reverse form. In the first consequence the logical reason "cold" negates "smoke," and in the second the logical reason "a variety of hair-raising" (spu long byed pa'i bye brag) negates "fire." The types involved are identified as B6 and B5 (B5 is the type of reason in the first consequence, B6 in the second). ${ }^{34}$ Thus, while B1-B4 are only illustrated once, B5 is illustrated once in the first part of the section with the pair "fire"/"hairraising" and once in the second part with the pair "cold"/"smoke," and B6 is illustrated twice, once in the first part of the section with the pair "hair-rising"/"fire" and once in the second part with the pair "variety of hair-rising"/"fire."

As mentioned above, RT3/RT4/RT5.1 add to their list of subtypes involving factual incompatibility one case involving conceptual incompatibility (B10). Regarding the former list, these versions further differ from RT1/RT2 by listing alongside B1-B6 also the three types B7-B9. As already mentioned, given that B79 induce a reverse form with a logical reason whose type is not legitimate, one would have rather expected to see them listed in the category "not inducing a probative argument."

Footnote 33 continued

"hoarfrost" negating "fire" in a consequence the reverse form of which would have a logical reason of type B1.

34 Both "hair-raising" and "a variety of hair-raising" are thus treated as the same element of the "cold group" (namely, an effect of cold) when it comes to identify the type of the logical reason. The specification might have just meant that the hair-raising under consideration is the effect of cold (rather than, for instance, other varieties of hair-raising, such as due to fear). But some commentators (such as g. Yag ston, cf. Rigs gter nyi snying 361b2-3) have taken the expression "bye brag" as indicating a subtype of effect, i.e., an additional element in the "cold group." Glo bo mkhan chen argues that if this case were to be distinguished on account of the formulation "a variety of hair-raising" rather than just "hair-raising," the identification of the type should be modified accordingly to "the apprehension of what is pervaded by the effect of something incompatible [with the negandum]" ('gal 'bras bu'i khyab bya* dmigs pa) (*Rigs gter nyi ma 256,18 contains the faulty reading khyab byed). The type of reason in the reverse form would be the "apprehension of the nature that is incompatible with the cause of the pervader [of the negandum]" (khyab byed kyi rgyu dang 'gal ba'i rang bzhin dmigs pa) (Rigs gter nyi ma 256,15-19). Note that such subtypes of apprehension of something incompatible are not discussed by Sa skya Pandita. However, one should keep in mind that 'U yug pa rigs pa'i seng ge considered four types of apprehension of the opposite based on "what is pervaded by the effect" or on a "specific effect." Unfortunately, 'U yug pa's commentary on the classification of consequences does not shed any light on this point. 
In the first portion of Part B, these versions list six types in the order B1, B5, B7, B3, B8, B9, each with an example (an element of the "heat group" negating an element of the "cold group"). Unlike in RT1/RT2, each mention counts for one type, the type of the logical reason in the consequence. In the second portion (where RT1/ RT2 repeat some or all of the previous types), they add three illustrations (again with an element of the "heat group" negating an element of the "cold group") that exemplify types B6, B2 and B4. The illustrations considered here are the same as in this part of the section in RT1. But they are said to represent three types (those of the logical reasons in the consequences), whereas RT1 arrives at a count of six (two types per pair of elements). Another difference to RT1 is that these three types are not identified by a particular name. Each case is referred to as being "similar" (mtshungs, 'dra) to one of the illustrations of B5, B1 and B3 respectively in the first section of Part B. It is thereby acknowledged that the pairs B1/B2, B3/B4 and B5/B6 are types that induce each other and can be found in both consequences and reverse forms, whereas B7, B8 and B9 are only considered in consequences.

\subsubsection{Verses and Autocommentary on the Number of Instances Per Category}

\section{Variants in the Numbers Given in the Verses}

As visible in Table 2, the number of symmetric and asymmetric types announced in the verses differ in the versions considered. In the same version, the number given in the verses in the text with the autocommentary may differ from the number given in the text of the verses alone. The following three pairs of numbers are found:

Table 2 Count of the instances in each category

\begin{tabular}{|c|c|c|c|c|c|c|c|}
\hline \multicolumn{6}{|c|}{ Sa skya Pandita } & \multirow[t]{3}{*}{ Phya pa } & \multirow[t]{3}{*}{ mTshur ston } \\
\hline \multirow[t]{2}{*}{$\mathrm{RT}_{\mathbf{v}}$} & RT1 & \multirow[t]{2}{*}{$\mathrm{RT}_{\mathbf{v}}$} & \multicolumn{2}{|c|}{ RT2 } & RT3/RT4 & & \\
\hline & A & & $\mathrm{V}$ & A & $\mathrm{A}$ & & \\
\hline
\end{tabular}

Number of distinct legitimate reasons being considered

$20 \quad 18 \quad 22$

Not inducing a probative argument

\begin{tabular}{|c|c|c|c|c|c|c|c|c|c|}
\hline 3 & 3 & 3 & 3 & 3 & 3 & 3 & 3 & 5 & 2 \\
\hline \multicolumn{10}{|c|}{ Inducing a probative argument } \\
\hline & & 20 & & & 20 & & & 13 & 20 \\
\hline \multicolumn{10}{|c|}{ Symmetric } \\
\hline 4 & 5 & 4 & 5 & $4 / 5 ?^{\alpha}$ & 5 & 4 & 4 & 3 & 4 \\
\hline \multicolumn{10}{|c|}{ Asymmetric } \\
\hline 16 & 16 & $16 \mathrm{i}(10 \mathrm{t})$ & 16 & 16 & $12 \mathrm{i}(10 \mathrm{t})$ & 14 & $14 \mathrm{t}$ & 10 & 16 \\
\hline
\end{tabular}

\footnotetext{
${ }^{\alpha}$ See note in Appendix 3, [1.2.3.2.a]
}

Symbols used in the table: V Verse in the version of the text containing the verses with the autocommentary, A Prose autocommentary, i Illustration, t Type 
- $4 / 16$ in $\mathrm{RT}_{\mathrm{v}}$

- 5/16 in RT2 $2_{\mathrm{v}}$ (and probably RT2) and RT1

- 4/14 in RT3 and RT4

For the number of types that induce a probative argument, the half-verse concerned only speaks of "all the remaining correct logical reasons" (lhag ma yang dag gtan tshigs kun), which is interpreted in various ways in the autocommentary of the various versions:

RT1/RT2 omit to comment on the expressions "remaining" (lhag ma) and "all" (kun) and give "twenty" as the number of types inducing a probative argument.

It is to be known that (the) twenty correct logical reasons explained previously induce a probative argument.

Here the expression "the twenty correct logical reasons explained previously" cannot refer to the list of legitimate reasons in the tenth chapter (cf. Sect. 1.1.3), since the types that do not induce a probative argument have already been taken out of this list. If it in fact referred to that list, one would rather have preferred to read, more explicitly, "twenty among the correct logical reasons previously explained."

RT3/RT4 represent an interpretation that is more intuitive:

It is to be known that among the twenty correct logical reasons explained previously, the remaining types (after removing) the three-non-apprehension of the nature, of the effect and of the definiens, which is a specific case of nonapprehension of the pervader-induce a probative argument.

Here the number of types inducing a probative argument is the total number of legitimate types - the expression "the twenty correct logical reasons explained previously" can easily be understood to refer to the list of legitimate reasons established in the tenth chapter-minus the number of types that do not induce a probative argument. The sum of symmetric types (4) and asymmetric types (14) yields eighteen as the number of types inducing a probative argument. Since the total number of legitimate types is given in these versions as "twenty," one must understand that the three cases listed in the category "not inducing a probative argument" actually count as two types only.

The phrasing in RT3/RT4, while unproblematic as such, strikes me as redundant with the previous paragraph (on the types that do not induce a probative argument, which are listed here again), and might suggest the intrusion of an explanatory note. Interestingly, the phrasing of RT3/RT4 is similar to the reading of the parallel passage in mTshur ston's sGron ma (Appendix 2, §2) (mutatis mutandis, as mTshur ston starts from a count of twenty-two types and sets aside only two as improper):

Among the twenty-two correct logical reasons already explained above previously, the remaining ones apart from the two-non-apprehension of the nature and non-apprehension of the effect-are twenty.

However, in sGron ma the list of the improper types in the sentence is not redundant, because mTshur ston deals with the explanation of improper types in the paragraphs that follow (Appendix 2, §3 and $\$ 4$ ), not those that precede. 
Discrepancies Between the Numbers Given in the Verses and the Autocommentary Onoda (1986) has already pointed out the discrepancy not only between the numbers given in the verses in the different versions, but also between these numbers and the logical reasons listed in the autocommentary.

RT1 lists four symmetric cases in the autocommentary, which matches the number in $\mathrm{RT} 1_{\mathrm{v}}$, whereas the verse in RT1 reads "five." For asymmetric cases, RT1 lists two types in Part A and two in Part C, while in Part B twelve illustrations are found for the six types B1-B6 (cf. Sect. 2.3.3.b). RT1 thus arrives at the number "sixteen" given in the verse both in RT1 and RT $1_{v}$. However, this count confuses "types" properly speaking and "illustrations.",35

RT2 arrives at a list of five symmetric cases with the mention of S5, which matches the number in the verse in $\mathrm{RT}_{2}$ (and probably RT2). Given how problematic S5 is (see Sect. 2.3.2.c), it appears to be a mistaken attempt to correct a text listing only four cases to arrive at five types in this category. The autocommentary, on the other hand, fails to arrive at the number "sixteen" for asymmetric types, as it lists neither sixteen types nor sixteen illustrations.

RT3/RT4 are the versions that fare best with regard to the coherence between the verses and the autocommentary. The autocommentary lists four symmetric types, and lists and illustrates fourteen asymmetric types: two in Part A, two in Part C and ten in Part B.

\subsection{Summary of the Problems}

The above analysis has exposed the various problems found in all the versions considered. These are, in summary:

- Logical mistakes RT3/RT4/RT5 do not correctly illustrate the reverse form of S4 and B10. RT2 does not correctly identify the type of the logical reason when illustrating S5 and wrongly classifies it as symmetric.

- Problems of consistency with the tenth chapter RT1 and RT2 do not include the legitimate types B7, B8 and B9 in their classification; RT3 and RT4 classify them as

\footnotetext{
35 Śākya mchog ldan clearly makes this distinction. He explains that in version (1) only fourteen types are distinguished: four that are symmetric (this takes into account the distinction between conceptual and factual incompatibility for one case) and ten that are asymmetric. But the latter ten give rise to a total of sixteen distinct illustrations, the six types of apprehension of something incompatible (B1-6) being illustrated twice. See Pham byed 189a1. Rol mtsho 145b6-7: ming mi mthun pa ni nyi shu bgrang du med kyang | 'phen lugs mi gcig pa'i sgo nas nyi shur phye ba yin no ||. On the reduction to fourteen types, see also Pham byed 187a 1-3: de ltar thal 'gyur nyi shu'i nang nas | bzlog phyogs la thal 'gyur yang dag tu rung ba dang mi rung ba du zhig yod ce na | bzlog phyogs la thal 'gyur yang dag tu mi rung ba lnga ste | lnga po gang zhe na sgrub byed mi 'phen pa'i thal 'gyur du bshad pa rnams so || cig shos phyogs la | thal 'gyur yang dag tu rung ba ni lhag ma bcu bzhi po rnams so $\|$ (to arrive at the initial total number of twenty, the second kind of apprehensions of something conceptually incompatible mentioned by Sa skya Pandita in the tenth chapter must be taken into account).

In Phya pa's and mTshur ston's works, the numbers that were given in the course of the classification are the numbers of types strictly speaking, in other words, those referred to by distinct expressions, regardless of the implicit subtypes (i.e., regardless of the distinction conceptual/factual in the case of the expression "incompatibility") and regardless of the (in fact endless) possibilities of illustrating these types. Phya pa, in particular, counts eighteen distinct types when distinct expressions are considered, and twenty-four when the cases involving conceptual incompatibility are counted separately. See Hugon (2016b, pp. 892-893).
} 
asymmetric types inducing a probative argument, even though the logical reason of the reverse form would be of a non-legitimate type. All version mention (I3), which is not distinguished in the typology of logical reasons in the tenth chapter.

- Problems of coherence between the verses and the autocommentary RT1 arrives at a list of sixteen (the number given in the verse) by counting "illustrations" rather than "types" properly speaking. RT2 does not arrive at a list of sixteen at all. The autocommentary in RT1 lists four symmetric cases whereas the verse in the version with the autocommentary reads "five."

- Arithmetical problems in RT2 the sum of five symmetric and sixteen asymmetric types is twenty-one, while the autocommentary announces twenty types inducing a probative argument. In RT3/RT4 the sum of four and fourteen (i.e., eighteen) is supposed to correspond to the total number of types minus the types that do not induce a probative argument (i.e., 20-3).

My general assessment of the versions considered is that RT3/RT4 offer the most coherent presentation, but they involve a number of logical mistakes and, more importantly, a problematic treatment of types B7-B9. RT1 is much less coherent, especially in its listing in Part B that confuses types and illustrations-which looks like an awkward attempt at arriving at the number sixteen given the verse for asymmetric reasons-and it also problematically omits to classify types B7-B9. RT2 fares even worse than RT1, as it involves a major logical mistake (S5) and incoherence between the verses and the autocommentary regarding the number of asymmetric reasons.

\section{Mathematics for Commentators}

Tibetan scholars were well aware of several diverging versions of the text for the passage of the Rigs gter on the classification of consequences.

Among the earliest evidence I could locate in this regard, Blo gros mtshungs med (fourteenth century) mentions two versions of the Rigs gter in his Tshad ma'i don bsdus pa: one with a four-by-fourteen model (as in RT3/RT4), one with a five-bysixteen model (as in RT2) (these numbers refer to the number of symmetric and asymmetric types; see Sects. 2.3.2, 2.3.3 and 2.3.4). ${ }^{36}$

\footnotetext{
${ }^{36}$ See Tshad ma'i don bsdus pa 59b3-4. Regarding this point, Blo gros mtshungs med mentions the explanation of Slob dpon Phyogs glang gsar ma Byams pa mngon po. In the biography of dKa' bzhi pa Rigs pa'i seng ge (1287-1375) by his pupil Seng ge bzang po, Phyogs glang gsar ma is mentioned to have been renowned in Sa skya for his expertise on the Rigs gter (cf. van der Kuijp 1993a, p. 285, n. 15). Phyogs glang gsar ma's commentary on the Rigs gter, entitled Tshad ma rig pa'i gter gyi rnam par bshad pa sde bdun dgongs gsal rigs pa'i 'brug sgra, is listed in the 'Bras spungs dkar chag under No. 016466, but to my knowledge it has not yet been published. Kano (2016, p. 320) discusses the identity of four persons named Blo gros mtshungs med, arguing that they are all different personae. Given the reference to Phyogs glang gsar ma, the derogatory remarks about the "followers of the summaries" ( $b s d u s$ pa ba) in opposition to the "followers of the Rigs gter" (rigs gter ba) and the fact that, according to its colophon, the Tshad ma'i don bsdus pa was completed in dPal Sa skya'i gtsug lag khang (61b5), its author is probably to be identified as Blo gros mtshungs med gNas drug pa (rather than Blo gros mtshungs med gSang phu pa), who was active at least between 1330 and 1371 (see Kano 2016, pp. 320 and 322-323).
} 
As previously noted by van der Kuijp (1993a), Bo dong Pan chen (1376-1451) was aware as well of conflicting versions for the eleventh chapter of the Rigs gter. His discussion of the classification of consequences in his Tshad ma rigs pa' $i$ snang $b a$ is relevant both in terms of the extent of this scholar's knowledge of the existing versions and interpretations, but also in terms of his own solution (which would deserve a separate discussion). ${ }^{37}$ The first model he discusses (270a3-271b2), with five symmetric and sixteen asymmetric reasons, recalls RT2. However, the fifth case of symmetric reason that is listed does not correspond to S5 in RT2 (see Sect. 2.3.2. c) (its type is khyab byed 'gal ba'i 'bras bu dmigs pa= B3). Also, the way to arrive at sixteen asymmetric cases matches neither the autocommentary in RT1 nor RT2. ${ }^{38}$ The second model he discusses $(271 \mathrm{~b} 2-273 \mathrm{a} 4)$ is the four-by-fourteen model. The list of the fourteen asymmetric types $(272 \mathrm{a}-\mathrm{b})$ corresponds literally to RT3/RT4. ${ }^{39}$ He briefly alludes to a third model counting three symmetric types, ten asymmetric ones and five that do not induce a probative argument (273a4-b1). These numbers correspond to Phya pa's model, but it is unclear whether it was Phya pa's model that Bo dong had in mind.

Onoda (1986) and Jackson (1991b, p. 25) note that Go rams pa and Śākya mchog ldan discuss the differences between various versions in their commentaries on the Rigs gter, composed in 1471 and 1474 respectively. Go rams pa (who adopts RT3, see below), knew also other versions of the text akin to RT1 and RT2. He criticizes commentators who adopt the reading 5/16 for the verses (Rigs gter rab gsal 326b12) as well as "contemporaneous Tibetans" (deng sang bod dag) who consider "twenty" to be the number of types inducing a probative argument (Rigs gter rab gsal 326a2-4). Śākya mchog ldan criticizes version RT3 as being "extremely incorrect" (ches shin tu ma dag pa). He himself adopts a version akin to RT1 in his Pham byed and Rol mtsho (144b2-146b1), although he notes that this version is not entirely correct either. ${ }^{40}$

Glo bo mkhan chen, whose commentary was composed in 1482 (van der Kuijp 1986, p. 54), mentions three versions of the verses - 4/16, 5/16, 4/14 — and knew of several versions of the autocommentary, including RT2. ${ }^{41}$

\footnotetext{
37 Tshad ma rigs pa'i snang ba 270a-275a. This passage was referred to in van der Kuijp (1993a, p. 287). Van der Kuijp (1993a, p. 283) indicates that Bo dong's knowledge of conflicting versions is also alluded to in his biography, composed in 1453 by his disciple 'Jigs med 'bangs.

38 According to Bo dong, the number sixteen is arrived by considering A1, A2, C1, C2, B1, B2, B5, B6 and their reverse form. This could be a modified version of RT2, in which B3/B4 is omitted from the list of asymmetric reasons, possibly due to B3 being (mistakenly) included among symmetric reasons.

39 Apart from a dittography on 272a2-3: du bas grang rgyu nus pa thogs med... phen pa dang I.

${ }^{40}$ Cf. Rol mtsho 145b6: 'di 'i skabs kyi 'grel pa la mi mthu pa gnyis snang bas | gcig kho na la rton par ni ma nus te | gnyis ka la yang yi ge ma dag pa'i skyon dang bcas pa du ma snang ba'i phyir ro ||. Cited in Onoda (1986, p. 77). See also van der Kuijp (1983, p. 19).

41 Cf. Rigs gter nyi ma 255,24-25: gzhung kha cig las... and Rigs gter nyi ma 256,15-19: gzhung phal che ba...
} 
Individual scholars writing on the topic follow one version or the other ${ }^{42}$ or propose original scenarios. ${ }^{43}$ Commentators of the Rigs $_{\text {gter }}{ }^{44}$ typically elect one version as the source text to be commented upon. Thus, the differences of interpretation between the commentators of the Rigs gter pertaining to the classification of consequences, such as the one between Săkya mchog ldan and Go rams pa noted by Onoda (1986), primarily resides in the fact that they have relied on different versions of the text. With respect to their explanations of this passage, these can be depicted as follows:

Relying on $\mathrm{RT}^{45}$ : lHo pa kun mkhyen (fifteenth century), Śākya mchog ldan (1428-1507) and Glo bo mkhan chen (1456-1532).

Relying on RT2: g.Yag ston Sangs rgyas dpal (1348-1414), his disciple Rong ston Shes bya kun rig (1367-1449) and rGyal tshab Dar ma rin chen (1364-1432). ${ }^{46}$ Relying on RT3/RT4: Go rams pa (1429-1489). ${ }^{47}$

Combining RT1/RT2 and RT3/RT4: Go rams pa's disciple Mus chen Rab 'byams pa (born in the fifteenth century).

As none of the versions provide an unproblematic reading (cf. Sect. 2.4), commentators are seen to adopt various strategies. Their main tactic is either to suggest emendations to the text they rely upon, or to keep the text they rely upon as it is and attempt to explain away the problems in a way that preserves logical consistency with the views that Sa skya Pandita advocates elsewhere (e.g., in the chapter on inference-for-oneself).

\footnotetext{
42 Van der Kuijp (1993a, p. 286) mentions that dGe 'dun grub pa (1391-1474) adopted the numbers four and sixteen for symmetric and asymmetric types, suggesting that he relied on RT3.

43 Van der Kuijp (1993a, p. 287) notably mentions that bCom ldan Rigs pa'i ral gri (ca. 1235-1314) accepted a total of seventeen types, four of which are symmetric and thirteen asymmetric, and that Bo dong pan chen adopted a three-by-eleven scenario. Bla ma dam pa bSod nams rgyal mtshan (1312-1375) knew RT3 with fourteen asymmetric types ( $b s$ Dus pa che ba 126a6-b2), but he himself adopted a fourby-five scenario, reducing the number of asymmetric types to B1, B3, B5, C2, A1 (bsDus pa gnyis pa 100b-101a; bsDus pa che ba 126b4-127a1). Blo gros mtshungs med's Tshad ma'i don bsdus pa (60a1) also gives five as the number of asymmetric types (but these are not listed).

44 For a list of commentaries on the Rigs gter, see Jackson (1983) and Hugon (2008, pp. 373-378). 'U yug pa's commentary is now available, but his discussion on this part of the Rigs gter (see Rigs pa grub pa 349-350) is very brief and does not allow any assumption about the nature of the version available to him.

45 Of course, the sDe dge version itself postdates these commentators by several centuries (see n. 13). When I speak of them "relying on RT1," I therefore mean that they have relied on a version of the text that corresponds to the one favored by the editor of the sDe dge print, at least for the passage under consideration.

46 Cf. respectively Rigs gter 'phro ba (264a5-265b6), Rigs gter nyi snying (360b2-361b5) and Rigs gter rnam bshad (144b5-146a3). Rong ston's commentary in all probability postdates that of his teacher $\mathrm{g}$. Yag ston. rGyal tshab's commentary also postdates g.Yag ston's commentary (cf. Dreyfus's introduction to Rigs gter rnam bshad, p. 7). The relative dating of Rong ston's and rGyal tshab's commentaries is less clear. When discussing the number of types that can be used in a consequence, Rong ston cites an interpretation that corresponds to the one found in rGyal tshab's commentary. However, since the citation is not literal it remains in question whether rGyal tshab's commentary indeed predates the one of Rong ston.

47 Rigs gter rab gsal 326a6-326b1: rigs gter rang 'grel hor spar gi rtsa 'grel gnyis char las 'di kho na bzhin 'byung ba'i phyir ro $\|$. Cf. Jackson (1987, p. 80, n. 24).
} 


\subsection{The "emending strategy"}

The "emending strategy" is typically adopted by Śākya mchog ldan and commentators relying on RT2. Śākya mchog ldan, who relies on RT1, ${ }^{48}$ suggests in particular:

i. to emend the number "five" given in the verse RT1 to "four," so as to match the number of cases listed in the autocommentary ${ }^{49}$;

ii. to add a half-verse mentioning types B7, B8 and B9 as additional types that do not induce a probative argument ${ }^{50}$;

iii. to emend the verse on the types inducing probans to tie it to the problematic passage in the autocommentary claiming that "the previously discussed twenty correct types induce a probative argument" so that the number refers to the "previously discussed correct consequences" from the preceding section. ${ }^{51}$

As for the three abovementioned commentators relying on RT2, their emendations consist in:

i. Proposing an alternative to the mistaken case S5 as a fifth symmetric type. rGyal tshab proposes the "apprehension of the cause of something incompatible with the effect [of the negandum] ('bras bu dang 'gal ba 'i rgyu dmigs pa) ${ }^{52}$ Rong ston the "apprehension of what is pervaded by the effect that is contradictory to the cause [of the negandum]" (rgyu dang 'gal ba'i 'bras bu'i khyab bya dmigs pa). ${ }^{53}$

\footnotetext{
48 The list of reasons in Pham byed (183b5ff), in particular the list of asymmetric reasons (Pham byed, 189a2-189b4), correspond to RT1, although the order differs. The summarizing table provided in Onoda (1986, p. 82) must be discarded as it involves numerous mistakes and does not reflect the list given by Śākya mchog ldan in Pham byed. Notably, Nos. 10,12,16 in Onoda's list of asymmetric cases repeat the cases 3,4,5 from the category of types that do not induce a probative argument, and symmetric case 3 is repeated as asymmetric case 14 .

49 Cf. Pham byed 185b1-186a2, discussed in van der Kuijp (1983, p. 19) and Onoda (1986, p. 77).

50 Rol mtsho (145a3-4): des na | gzhung 'di ltar yang sbyar te | 'bras bu dang ni 'gal ba yi || rang bzhin 'bras bu khyab bya ste || spang gnyen lhan cig mi gnas pa'i || 'gal dmigs gsum gyis sgrub mi 'phen || zhes so $\|$. The passage is mentioned in Onoda (1986, p. 84, n. 24). See also Pham byed 184a5-184b4. There Sākya mchog ldan states that one can thus count three additional cases that do not induce a probative argument, or six if one considers two alternative illustrations of these three types, one positing as a logical reason a member of the "heat-group," the other positing as a logical reason a member of the "cold-group."

51 Rol mtsho 145a7. In the preceding passage (Rol mtsho 145a6-7), Śākya mchog ldan explains that the Rigs gter speaks of the reasons used in consequences as "correct reasons" (yang dag pa'i gtan tshigs) because they lead the opponent to remember the three characteristics that enable him to carry out an inference.

52 Cf. Rigs gter rnam bshad 145b2-4. This type was included by mTshur ston in his list of symmetric reasons (No. 14), but this is because mTshur ston accepts the "apprehension of the cause" to be a distinct type of reason of non-apprehension. rGyal tshab recalls that such a reason is not a legitimate reason in a direct proof (according to Sa skya Pandita), but concedes that it can be acceptable in a consequence as long as it is accepted by the opponent. He does not comment on the fact that, this type being symmetric, the reverse form of such a consequence would then also involve a reason qua "apprehension of the cause."

53 Cf. Rigs gter nyi snying 361a2-3. This case is illustrated by the negation of an additional element to the "cold group," namely, "a specific type of hair-raising" (spu long gi bye brag), which negates "a specific type of smoke" ( $d u$ ba'i bye brag) (strictly speaking, the type should be termed khyab byed kyi rgyu dang 'gal ba'i 'bras bu'i khyab bya dmigs pa). This subdivision is reminiscent of 'U yug pa's model of reasons qua apprehension of something incompatible.
} 
ii. Adding illustrations of asymmetric types in order to arrive at the number sixteen. $^{54}$

iii. Taking the "twenty correct logical reasons" to refer to correct consequence (like Śākya mchog ldan, cf. iii above).

They do not, however, explain how the five symmetric cases and the sixteen asymmetric ones sum up to twenty rather than twenty-one.

\subsection{The "Explanatory Strategy"}

It is worth noting that 1 Ho pa kun mkhyen Rin chen dpal, who was a pupil of Sa skya Pandita, one of his biographers and one of the commentators chronologically closest to him, appears to have based his commentary on a version akin to RT1 (with the reading 4/16 for the verses and a double count of types B1-B6) which, as far as we can assess, he did not consider as corrupt. 1Ho pa's work of epistemology is not currently extant, but Glo bo mkhan chen cites in his commentary on the Rigs gter (Rigs gter nyi ma) some passages from this work (for which he gives the title sDe bdun gsal ba'i rgyan) in verse form to support his own understanding. Regarding asymmetric types, Glo bo mkhan chen writes: ${ }^{.5}$

Since this meaning is explained as follows by lHo pa kun mkyen in the $s D e$ bdun gsal ba' $i$ rgyan, it is trustworthy: "There are sixteen that induce [a logical reason] of a different type: The remaining six when one removes from the nine arguments in which the three elements of the "heat group" negate the three elements of the "cold group" the three that induce [a logical reason] of the same type, plus the two kinds of consequences relying on essential property and effect, make a total of eight, from which sixteen are distinguished."

\footnotetext{
54 g.Yag ston duplicates, for instance, $\mathrm{C} 1$ and $\mathrm{C} 2$ by considering one illustration based on the verb yin and one based on the verb yod (Rigs gter phro ba 265b1-6). Rong ston does something similar (Rigs gter nyi snying 361b1-4). rGyal tshab adds the type "essential property" (rang bzhin gyi rtags) when the logical reason is a definiens (e.g., "Because there are branches and leaves, it follows that it is a tree.") as well as its reverse form, the "non-apprehension of the nature" (rang bzhin ma dmigs pa' $i$ rtags). (Rigs gter rnam bshad 1456a2-3). The "non-apprehension of the nature" was rejected by Sa skya Pandita when posited to negate the nature itself (cf. I1). But here it is posited to negate the definiens.

55 Rigs gter nyi ma 256,7-12: don 'di ni lho pa kun mkhyen gyis sde bdun gsal ba'i rgyan las | sgrub byed 'phen pa nyi shu la || rang rigs 'phen pa rnam pa bzhi || gzhan rigs 'phen pa bcu drug ste || tsha reg gsum gyis grang reg gsum || 'gog pa'i spyod pa rnam dgu las || rang rigs 'phen pa rnam gsum bri || lhag ma drug dang rang bzhin dang || 'bras bu'i thal ba rnam gnyis te || brgyad las phye ba'i bcu drug nyid || ces gsungs pa ltar bshad pa yin pas khungs thub cing ||. This passage is cited in van der Kuijp (1993a, p. 285).

On Glo bo mkhan chen's own position, see Rigs gter nyi ma 255,6: de 'i lhag ma nyi shu pos ni sgrub byed 'phen par shes par bya'o zhes pa'i don to $\|$ and Rigs gter nyi ma 255,15-17: gzhan rigs 'phen pa ni 'gal dmigs bcu gnyis kyi nang nas grang $\mid$ me $\mid$ ba $\mid$ tsan $|d u|$ spu phan tshun 'gog pa'i sbyor ba gsum ma gtogs pa lhag ma drug dang | 'bras rang gi thal ba gnyis te brgyad las phye ba'i bcu drug yin la... Glo bo mkhan chen's illustrations of the six types of apprehension of something incompatible are the same as in RT1 but are listed in a different order, which probably reflects Glo bo mkhan chen's own rearrangement rather than an alternative version of the source text. The text contains many faulty readings in the identification of the types of logical reasons. For B2, Rigs gter nyi ma 255,19 reads rang bzhin 'gal ba' $i$ khyab byed dmigs pa, which should be corrected to rang bzhin 'gal ba'i khyab bya dmigs pa. For B6, Rigs gter nyi ma 255,19 reads rgyu dang 'gal ba'i 'bras bu dmigs pa, which should be corrected to rang bzhin dang 'gal ba' $i$ 'bras bu dmigs pa. For B4, Rigs gter nyi ma 256,3 reads rgyu dang 'gal ba'i khyab byed dmigs pa, which should be corrected to rgyu dang 'gal ba'i khyab bya dmigs pa.
} 
lHo pa can be said to adopt, like Glo bo mkhan chen after him, an "explanatory strategy," as he explains the number sixteen for asymmetric reasons as the sum of eight types (A2, B1-B6, C1) and the eight corresponding types in the reverse form (A1, B1-B6, C2) (this means that six types are counted twice).

Further, Glo bo mkhan chen considers that B7, B8 and B9 are subsumed under I2 in the category of types that do not induce a probative argument (because they would induce a direct proof involving a logical reason qua "apprehension of the cause") (Rigs gter nyi ma 256,20-21).

Go rams pa, the only commentator I know of who elects RT3 as his source text, also adopts an explanatory strategy to avoid the main problem of this version: the inclusion in the list of asymmetric types of B7, B8 and B9 (that induce illegitimate types, which I have noted as B7', B8', B9' in Table 1). In Part B, RT3 gives a list of types illustrated by an element of the "heat group" negating an element of the "cold group" in a consequence $\left(\mathrm{T}_{1}\right)$, together with the type induced $\left(\mathrm{T}_{2}\right)$. Go rams pa strategy is to rephrase this whole part, taking types $\mathrm{T}_{2}$ as the types of logical reasons in consequences and $\mathrm{T}_{1}$ as the types of reasons in the direct proofs they induce. This does not affect types B1-B6, but now the illegitimate types B7', B8' and B9' appear in the consequence and the legitimate types B7, B8 and B9 in the reverse form. ${ }^{56}$ While a direct proof with an illegitimate type of reason is clearly problematic, positing illegitimate types as logical reasons in consequences might be acceptable in view of Sa skya Pandita's definition of a "correct consequence" (Rigs gter XI, 363) that requires only that the logical reason is accepted by the opponent. ${ }^{57}$

Interestingly, Go rams pa divides the nine cases in Part B into three groups, the names for which refer to the type of the logical reason in the reverse form. This could suggest that Go rams pa understands the classification of consequences as a classification based on the type of reason occurring in the direct proof that is induced. This would explain why Sa skya Pandita did not mention the consequences involving types B7, B8 and B9, namely, because the non-legitimate types B7', B8' and B9' are not in the list of types taken as the basis for the classification. Classifying consequences based on the type of the logical reason in the reverse form is, so far I understand, the solution adopted by Go rams pa's student Mus chen Rab 'byams pa (who claims that this is his own idea). ${ }^{58}$ However, Go rams pa's explanation of the number "twenty" is that it refers to types of reasons in consequences (de dag gi ming can gyi thal 'gyur), even if the twenty types are those distinguished earlier for direct proofs. ${ }^{59}$ This is clearly the case when he discusses I1-I3 (i.e., these are the types of the logical reason in the consequence). Types B7'-B9' should therefore not figure in the classification. This deserves further investigation.

Solving the "mathematical problem" of RT3 (cf. Sect. 2.4), Go rams pa explains that twenty types minus three types that do not induce probans indeed yields the number seventeen; however, the number of types inducing probans is eighteen (4

\footnotetext{
56 Rigs lam rab gsal 327a4-328a2.

57 See also rGyal tshab's argument to this effect in n. 52.

58 See Rigs lam rab gsal 136b4-6: ... kho bo 'ba' zhig gi blo gros las byung ba'o $\|$.

59 Rigs gter rab gsal 325a4: spyir gtan tshigs yang dag la ... nyi shur grangs nges la $\mid$ thal 'gyur la yang de dag gi ming can gyi thal 'gyur nyi shur grangs nges so $\mid$.
} 
$+14)$, because I3 is a specific variety of one of the twenty types, which still figures among the types inducing probans $(=\mathrm{C} 2) .{ }^{60}$

\section{Conclusion: What Happened to the (Conjectural) "Original Version"?}

If the divergences between commentators can satisfactorily be explained by the fact that they have relied on different versions of the Rigs gter and attempted to palliate their respective problems by individual strategies, we yet must face the question of the origin of the divergent versions and their not supporting in a strong way a "logical scenario" such as the one evoked in Sect. 2.1. Commentaries on the Rigs gter are helpful in indicating readings from manuscripts that are unavailable to us and in pointing out logical problems and issues of internal consistency. But they do not concern themselves with the genesis of the faulty versions they discuss, other than identifying them as the result of corruption of a putative original version.

Van der Kuijp (1986) has noted the existence of a version of the Rigs gter in thirteen chapters known to Bla ma ldong ston, the earliest commentator on the Rigs gter, which might have been quite different from the versions known to us, although the differences (of structure at least and possibly of contents as well) appear to have concerned principally the part on the theory of definition (mtshan nyid). This notwithstanding, there might have been several versions of the Rigs gter in circulation in the thirteenth century. The versions examined here could be witnesses of this multiplicity. However, two features of these versions must be highlighted:

First, as far as I could establish based on the dpe bsdur ma editions, the passage on the classification of consequences considered here is the only place where RT1, RT2 and RT3/RT4 differ to such a degree and for such an extended portion of text. The divergence actually extends to the following section, on fallacious consequences (gnyis pa thal 'gyur ltar snang), which is missing in RT3ii, RT4 and RT5. ${ }^{61}$ These versions jump from the end of the discussion on the classification of consequences based on the type of the logical reason (which is the last subsection in the section on correct consequences, thal 'gyur yang dag) to a section rejecting objections pertaining to the definition of correct and fallacious consequences (gsum pa rtsod pa spang ba). ${ }^{62}$ All versions agree again with one another from this point onwards all the way up to the end of the text a few folios later.

Secondly, none of these versions offer a satisfactory reading for the passage under consideration. The conflicting accounts are all faulty to some extent. While no version falls into the category "completely corrupt," 63 they do all suffer from the

\footnotetext{
60 Rigs gter rab gsal 325b6-7. Cf. Onoda (1986, p. 77).

61 Rigs gter dpe bsdur ma 1 and 2 do not indicate that this portion is missing in RT2, RT6 or RT3i. But according to Rigs gter dpe bsdur ma 2 the verse line that is part of this section is missing from the text of the verses only in RT2 and RT6.

62 Several commentators (including g.Yag ston and Glo bo mkhan chen) omit to comment on the section on fallacious consequences, but this might also be explained by the lack of necessary explanation on this short section.

63 An instance of a "completely corrupt" presentation would be that found in gTsang nag pa's bsDus pa, see Hugon (2016b, §2.2).
} 
kinds of fault that go well beyond a momentary lack of attention by the author or a scribe (which would be understandable given the highly "technical" nature of the passage). ${ }^{64}$ While I have no problem in accepting that there was not one original Rigs gter but that several competing versions of the Rigs gter coexisted in the thirteen century, I have a harder time conceding that any of the versions of the passage examined above are from the hand (or voice) of Sa skya Pandita himself. But I concede this might stem from an overly idealistic representation of the author.

Keeping in mind the question of the identity of the "final redactor" of each version, I would like to propose a scenario accounting for the constitution of the extant versions, in particular RT1 and RT3. This scenario suggested itself while I was comparing the text of the Rigs gter with parallel discussions in the works of Sa skya Pandita's predecessors. Two things in particular struck me:

- On one hand, Sa skya Pandita's model is quite similar to that of Phya pa. Yet, this is not reflected in the numbers given for the instances in each category in his classification.

- On the other hand, the numbers of types per category given in $\mathrm{RT} 1_{\mathrm{v}}$ are identical to those in mTshur ston's sGron ma, namely, twenty inducing a probative argument, four of which are symmetric and sixteen asymmetric types. Yet, mTshur ston and Sa skya Pandita propose quite different systems, because they disagree on the range of legitimate types due to their diverging stand regarding the "apprehension of the capable unimpeded cause" (cf. Sect. 1.1.2.a).

That the numbers in the Rigs gter do not match those in Phya pa's classification is primarily explainable by the fact that the numbers in Phya pa's classification of consequences strictly refer to distinct expressions of types; this means that Phya pa does not count separately one or several subtypes of non-apprehension involving conceptual incompatibility (as done in all the versions of the Rigs gter) and does not confuse types strictly speaking and illustrations (as done by RT1).

It might be more than a mere coincidence that the numbers in $\mathrm{RT} 1_{\mathrm{v}}$ (and in $\mathrm{RT} 1$ if the number of symmetric types in the verse is corrected to "four" based on the autcommentary) match those in mTshur ston's classification. mTshur ston was one of Sa skya Pandita's first teachers of epistemology around the years 1201-1203 (Jackson 1987, pp. 26, 106), and it is likely that at that time Sa skya Pandita studied mTshur ston's sGron ma. ${ }^{65}$ mTshur ston had a large formative influence on his pupil, even though the latter moved on to largely refute his ideas (his particular ideas as well as the ideas representative of the mainstream tradition linked with gSang phu scholars). There is still a large bulk of the earlier Tibetan tradition that found its way into Sa skya Pandita's system. More particularly, in terms of writings, the sGron ma appears to have served as a model to Sa skya Pandita (maybe together with other texts) when he was composing the Rigs gter, a model both in terms of the structure of presentation (i.e., the sa bcad divisions on a large or small scale) and in terms of the contents. To say that Sa skya Pandita's Rigs gter was "influenced by the sGron ma" is an understatement. There is manifold evidence of Sa skya

\footnotetext{
${ }^{64}$ Mistakes of this type (notably regarding the expressions or the types of logical rasons) are frequent, for instance, in the commentary of Glo bo mkhan chen (cf. n. 55).

65 On the question of the authorship of the sGron ma, see the introduction to the edition, xi-xii.
} 
Pandita "reusing" the sGron ma, in many cases literally so. ${ }^{66}$ This is the case when mTshur ston's position is cited as that of an opponent to be refuted, and an example of this is found in the discussion on the theory of definition. But textual reuse is also found in other cases where Sa skya Pandita simply agrees with mTshur ston's presentation and repeats it more or less verbatim. A prominent example of this phenomenon was presented in Hugon (2004, pp. xiii-iv). It was clear in the analyzed passage that the verses of the Rigs gter were subsequently composed to complete the already existing prose, a passage from the $s$ Gron $m a$ that Sa skya Pandita was reusing without any change. Keeping this example in mind, I would like to propose as a working hypothesis that the passage on the classification of consequences might originally have been of a similar nature, namely, a reuse of the $s$ Gron ma. However, given Sa skya Pandita's disagreement with mTshur ston on background issues, it could not be a simple literal reuse. One may thus envisage the following process:

Step 1 Sa skya Pandita silently imports the passage of the sGron ma on the classification of consequences (cf. Appendix 2) with several initial modifications: the addition of case I3 to the two cases listed in the sGron $m a$ in this category (sGron ma \$2-4), the suppression of the final paragraph (sGron ma §22) and the change of place of the section $\S 16$.

Step 2 Verses are composed to summarize the prose text. As they are still based on the prose from the sGron ma, they give the number "four" for symmetric types (cf. sGron ma §6) and "sixteen" for asymmetric types (cf. sGron ma §11).

Step 3 Given the disagreement on legitimate types, sGron ma's fourth symmetric type (No. 14, sGron ma §10) is replaced by S4a and the asymmetric types listed in $s$ Gron $m a \$ 21$ are replaced by a repetition of the six types already listed ( $s$ Gron $m a \S 18-20)$ with other illustrations. The passage of the autocommentary on the number of types inducing a probative argument is modified to preserve the idea " $4+16=20$," without spelling out the total number of types from which the number of types that do not induce a probative argument is substracted (In sGron ma $\S 2$, the number of types inducing a provative argument was given as “ $22-2=20$ ”).

Alternatively, one can envisage that S4 was added to mTshur ston's list of symmetric types at step 1 and that the verse composed at step 2 therefore read "five." At step 3, mTshur ston's No. 14 was removed from the list of symmetric types, but the reading "five" remained in the verse although the autocommentary now only listed four types. This now mistaken "five" was later corrected to "four" in some versions (such as the one known to lHo pa kun mkhyen) but was retained in others (such as the one reflected in the sDe dge print). In RT2 a fifth type was added in the autocommentary to make up for the inconsistency between verse and autocommentary.

This process would have generated a version corresponding to RT1 (and then, through additional modifications, a version like that in RT2). This is indeed the version that is the closest in its formulation (in many cases literally identical) to the parallel paragraphs in the sGron ma (see in particular the portions parallel to $s$ Gron ma $\S 8,9,12,13,14,16,18$ 20). This process would explain quite well why the types B7-B9 are missing in RT1:

\footnotetext{
66 See Hugon (2015) on the widespread phenomenon of reuse, in particular in the form of a silent import of passages from another work, in the composition of texts in the Tibetan tradition, with examples from early epistemological works.
} 
since they were not included by mTshur ston in the category of types that are improper in consequences ( $s$ Gron $m a \S 2-4$ ), they are likewise absent in the corresponding category by Sa skya Pandita. However, while they are found in the category of asymmetric types in the sGron ma (sGron ma $\$ 21$ ), which is removed at step 3, they were not at this stage reintroduced among types that do not induce a probative argument.

I readily concede that there is much that is questionable about the hypothetical process sketched above. The main problem is the difficulty to explain why some modifications would be effected at step 1 (before composing the verses), while others and actually more important ones would be effected only at step 3 (after composing the verses). If it is supposed that the modifications following step 2 are the deeds of a disciple of Sa skya Pandita who felt that keeping true to the verses was essential, we are also bound to accept that Sa skya Pandita had issued a text that was logically inconsistent. Under the assumption that Sa skya Pandita himself was responsible for the changes at step 3, we are ascribing to him modifications that have generated a version of the autocommentary that is far from optimal (especially in Part B) and apparently guided by the need to match the existing verses.

One could regard RT3/RT4 as a distinct attempt to revise an existing problematic version arrived at during step 2, in which the liberty was taken to change the initial verses together with emending the autocommentary. Importantly (and problematically) the types listed in sGron ma \$21, i.e., B7-B9, are retained in Part B in these versions. Versions RT3/RT4 would also stand out as a freer reuse of the sGron ma, or more likely of an initial version of the Rigs gter at step 2. If the difference between RT3i and RT3ii is confirmed, RT3i would represent an intermediate version between RT1 and RT3ii/RT4.

The presence, in RT5, of two additional notes that are quasi-literal citations of the sGron $m a$ ( $\$ 3$ and $\S 14)$ is an additional element worth mentioning, although its connection to the whole process of composition and edition remains in question.

My hypothesis leaves us with one scenario in which Sa skya Pandita composed an initial faulty version, which was later revised (in several ways) by his disciples, and one scenario in which Sa skya Pandita himself is responsible for the "questionable" portions of RT1 - "questionable" in our analysis, but not from the point of view of a direct student of Sa skya Pandita such as lHo pa. If these scenarios are rejected on account of an "idealistic" image of the author, one might fall back on the hypothesis of a hectic transmission of this part of the text which led to the stepping in of other "hands" or "voices" (for instance, one could suggest, to fill in a part of the autocommentary that got lost or for some other reason was left by the author to be completed by his students). But a major question remains in such a case: why is this the case only in this part of the text?

Perhaps alternative versions of the text that have not been considered here may shed further light on the genesis of the various versions of this passage in the Rigs gter (or further complicate the problem). However, given that none of the commentators and Sa skya pa scholars writing on the topic seem to have known another version that would be closer to the ideal "logical scenario," I have some doubt that such a version of the text was preserved, provided that it ever existed in the first place. Nevertheless, I hope to have shown that a systematical analysis of the works of Sa skya Pandita's predecessors constitutes a promising way of approaching such kind of question. Their impact should rightly be appreciated not only from the perspective of a history of ideas but also at the level of the very formulation of these ideas in text composition. 
Acknowledgements Open access funding provided by Austrian Science Fund (FWF). Part of the work on this paper has been generously supported by the Austrian Science Fund (FWF) in the context of the project P23422-G15 "Early bKa' gdams pa scholasticism." I am grateful to Tsering Drongshar for his help in locating additional material and making sense of the editorial conventions adopted in the dpe bsdur ma editions. My thanks to Dennis Johnson for improving my English. I am responsible for the remaining errors.

Open Access This article is distributed under the terms of the Creative Commons Attribution 4.0 International License (http://creativecommons.org/licenses/by/4.0/), which permits unrestricted use, distribution, and reproduction in any medium, provided you give appropriate credit to the original author (s) and the source, provide a link to the Creative Commons license, and indicate if changes were made.

\section{Appendix 1: Hierarchical Structure of the Overarching Section in the Rigs gter with Reference to Rigs gter dpe bsdur ma 1}

rang 'dod pa $(419,8)$

1. thal 'gyur yang dag $(419,10)$

1.1 mtshan nyid $(419,10)$

1.2 dbye ba $(419,12)$

1.2.1 sgrub byed 'phen pa $(419,12)$

1.2.2 sgrub byed mi 'phen pa $(422,7)$

1.2.3 de dag gi dbye ba dper brjod pa $(422,9)$

1.2.3.1 sgrub byed 'phen pa dang mi 'phen par dbye ba $(422,9)$

1.2.3.2 sgrub byed 'phen pa la rang rigs gzhan rigs gnyis su dbye ba $(423,3)$

1.2.3.2.a rang rigs 'phen pa $(423,4)$

1.2.3.2.b gzhan rigs 'phen pa $(423,18)$

2. thal 'gyur ltar snang $(426,3)$

\section{Appendix 2: Passage on the Classification of Consequences in mTshur ston's sGron ma}

\section{sGron ma 65b7-66a8}

1 gnyis pa brjod byas dbye' na

2 sngar gong du bshad zin pa'i yang dag pa'i rtags 65 b8 nyi shu rtsa gnyis las I rang bzhin mi dmigs pa (No. 21) dang 'bras bu mi dmigs pa (No. 22) gnyis ma gtogs pa lhag ma nyi shu yin no ॥

3 rang bzhin mi dmigs pa (No. 21) ni bsgrub pa'i thal bar mi rung ste I 'di ltar sa phyogs na bum pa ma dmigs pa'i phyir med par thal lo zhes brjod na I pha rol gyis sa phyogs na snang rung gi bum pa yod par grub pam ma grub I snga ma ltar na dmigs par yang grub pas shes 'dod med la I phyi ma ltar na thal ba'i dam bca' la bsal pa med cing rang rgyud kyi phyogs chos mi 'grub pa'i 65 b9 phyir ro II

4 'bras bu mi dmigs par (No. 22) yang mi 'gyur te I'di na $d u$ ba med pa'i phyir du ba'i rgyu nus pa thogs med kyi me med par thal zhes brjod pa na I du ba'i rgyu nus pa thogs med yod par grub na 'bras bu du ba yang grub zin pas bzlog pa la shes 'dod med la I ma grub na thal ba'i dam bca' la bsal pa med pas bzlog pa'i rtags mi 'grub pa'i phyir ro ॥ 
sGron ma 65b7-66a8

5 gsum pa byed pas dbye' na gnyis ste I bzlog pa rang rigs 'phen pa dang | gzhan rigs 'phen pa'o ||

6 de la rang rigs 'phen ${ }_{66 a 1}$ pa ni bzhi ste I

7 grang reg yod pas me med par thal zhes pa'i rang bzhin 'gal ba dmigs pas (No. 11) thal ba las me yod pas grang reg med ces pa'i rang bzhin 'gal ba dmigs pa (No. 11) nyid 'phen pa dang I

8 ba mo'i reg pa yod pa'i phyir tsan dhan gyi me med par thal zhes pa'i khyab byed 'gal bas khyab pa dmigs pas (No. 12) thal ba las tsan dan gyi me yod pa'i phyir ba mo'i reg pa med ces pa'i khyab byed 'gal bas khyab pa nyid (No. 12) 'phen pa dang I

9 spu long byed pa yod pa 'i phyir du ba med par thal zhes pa'i rgyu dang 'gal ${ }_{662}$ ba' $^{2} \mathbf{\text { 'bras }}$ bu dmigs pas (No. 13) thal ba las du ba yod pa'i phyir spu long byed pa med ces rgyu dang 'gal ba'i 'bras dmigs nyid (No. 13) 'phen pa dang I

10 grang reg gi rgyu nus pa thogs med yod pa'i phyir me rgyu nus pa thogs med med par thal zhes pa'i 'bras bu dang 'gal ba'i rgyu dmigs pas (No. 14) thal ba las me rgyu nus pa thogs med yod pa'i phyir grang reg gi rgyu nus pa thogs med med ces pa'i 'bras bu 'gal ba'i rgyu dmigs nyid (No. 14) 'phen pa yin no $\|$

11 gzhan rigs 'phen pa ni bcu drug ste I

12 de yang re shig du ba yod ${ }_{66 а 3}$ pas me yod ces pa'i 'bras rtags (No. 2) dang I me med pa' i phyir du ba med ces pa'i rgyu mi dmigs pa (No. 1) gnyis la mtshon na I thal bzlog gnyis phan tshun gyi bsgrub bya log pa gtan tshigs yin zhing I gcig gi rnal khyab cig shos kyi bzlog khyab yin pas khyab pa 'brel zhing phyogs chos 'gal ba dag gzhi' cig gi steng du bsgrub bya khegs bzhin du rtags khas len pa la gcig thal bar brjod pas cig shos rang rgyud du 'phen te I

13 la la du ba mthong bzhin du me med ces zer ba la me med pa'i phyir du ba ${ }_{66 a 4}$ med par thal zhes pa'i rgyu mi dmigs pa'i (No. 1) thal bas $d u$ ba yod pa'i phyir me yod ces pa'i 'bras rtags (No. 2) rang rgyud du 'phen la I

14 me khegs bzhin du du ba yod par smra ba la du ba yod pa 'i phyir me yod par thal zhes pa'i 'bras bu'i (No. 2) thal bas me med pa'i phyir du ba med ces pa'i rgyu mi dmigs pa (No. 1) rang rgyud du 'phen pa yin no II

15 de'i tshe du yod tshad mas grub na rgyu mi dmigs pa'i bsgrub bya la bsal cing 'bras rtags kyi phyogs chos grub la I me med tshad mas grub na 'bras rtags kyi bsgrub bya la bsal zhing rgyu 6655 mi dmigs pa'i phyogs chos grub pa yin no II

16 tshul 'di nyid sbyar te sha pas shing sgrub pa dang shing bkag pas sha pa 'gog pa rang bzhin (No. 5) dang khyab byed mi dmigs pa (No. 6) gnyis phan tshun 'phen pa dang I

17 'gal dmigs bcu drug las kyang 'gal ba'i skor nas

18 me dang ba mo'i reg pa phan tshun 'gog pa khyab byed 'gal ba dmigs pa (No. 7) dang 'gal bas khyab pa (No. 8) gnyis dang I

19 du ba dang ba mo'i reg pa phan tshun 'gog pa khyab byed 'gal ba'i 'bras bu dmigs pa (No. 9) dang rgyu dang 'gal bas khyab pa (No. 10) gnyis dang I

20 me dang spu long ${ }_{66}$ byed pa phan tshun 'gog pa rgyu dang 'gal ba dmigs pa (No. 4) dang rang bzhin 'gal ba'i 'bras bu dmigs pa (No. 3) gnyis dang ।

21 rgyu skor nas

me dang grang reg gi rgyu nus pa thogs med phan tshun 'gog pa 'bras bu 'gal ba dmigs pa (No. 15) dang 'gal ba'i rgyu dmigs (No. 16) gnyis dang

tsan dan gyi me dang grang reg gi rgyu nus pa thogs med phan tshun 'gog pa 'bras bu 'gal bas khyab pa (No. 17) dang khyab byed 'gal ba'i rgyu dmigs (No. 18) gnyis dang I

du ba dang grang reg gi rgyu nus pa thogs med phan tshun 'gog pa 'bras bu 'gal ba'i 'bras bu dmigs pa (No. 19) dang $\left.\right|_{66 a 7}$ rgyu dang 'gal ba'i rgyu dmigs pa (No. 20) gnyis 'phen par byed pa yin no $\|$ 
sGron ma 65b7-66a8

22 de lta na rang bzhin la bzlog pa mi 'phen pa dang 66a8 rigs gzhan 'phen pa dang rang rigs 'phen pa dang gsum blta'o ॥

'bras bu la ni rang rigs 'phen pa mi srid de rtags su med dgag dgod du mi rung pa'i phyir ro ॥ rang bzhin la ni rang rigs 'phen pa yang srid ste I 'di ltar bum pa ma yin dgag gi tha snyad kyis stong pa'i phyir med dgag gi tha snyad du rung par thal ba las med dgag gi tha snyad kyis stong pa'i phyir ma yin dgag gi tha snyad du byar rung zhes 'phen pa lta bu ste rtags su med dgag dgod du rung pa' $\mathrm{i}$ phyir ro II

\section{Appendix 3: Tibetan text of the passage of the Rigs gter on the classification of consequences}

The text provided here is that of section [1.2.3] in the hierarchical structure of the overarching section (see Appendix 1). The page or folio references are:

RT1: 192a6-193b2

RT2, RT3i: in Rigs gter dpe bsdur ma 1422,9-426,2 and Rigs gter dpe bsdur ma 2 431,2-434,16

RT3ii: 186b6-188a3

RT4: 297a2-299a1

RT5: 277a3-280a2 (277b and 278a are missing)

RT6: in Rigs gter dpe bsdur ma 2 431,2-434,16

For the verses I also consider the reading of the Rigs gter in the versions containing the verses only, when available:

$\mathrm{RT}_{\mathrm{v}}: 24 \mathrm{~b} 1-2$

$\mathrm{RT}_{\mathrm{v}}$ and RT6 ${ }_{\mathrm{v}}$ : in Rigs gter dpe bsdur ma 2 44,18-45,1

The following conventions have been applied:

- Reference to parallel or identical passages in the sGron ma are indicated in the right column. The numbers refer to the numerotation of the paragraphs in Appendix 2.

- Examples of arguments appear in italics, as are the pairs of opposite elements to be used to construct such arguments

- Expressions for the type of the logical reason (or expressions standing for it) appear in bold and are followed, in parenthese, by the reference for this type from Table 1.

- Verses of the Rigs gter appear in bold.

- The text of the various versions is given in distinct columns in case of important variations. Minor variation are noted in parentheses after the word(s) concerned, which is underlined.

- RT2, RT3i and RT6 indicate readings that are explicitly marked as such in the comparative recensions. When no variant is explicitly given in the comparative 
recensions, the reading of these versions is to be assumed to side with RT1. In such cases, I refer to the reading as "RT1/2," "RT1/3i," and "RT1/6" respectively. The same applies to the reading of the text with the verses alone. Doubtful cases are discussed in the notes that follow the edition.

- The notation "dpe bsdur" is used to refer to a reading of Rigs gter dpe bsdur ma that differs from the sDe dge edition but is not marked as the reading of RT2, RT3i or RT6. Some cases are faulty readings in the sDe dge edition, others may be editorial mistakes in the dpe bsdur ma or may represent readings from other manuscripts consulted by the editors.

- Marginal notes in RT5 appear in pointed brackets and are referred to with an asterisk.

- Variations in punctuation are not recorded.

- Orthographical variations (e.g., cig/gcig, zhes/ces) and orthographic particularities of RT3ii (e.g., myi for mi, tsha dhan for tsan dan, etc.) are not recorded among the variants.

\section{[1.2.3]}

Rigs gter dpe bsdur ma 1 422,9; Rigs gter dpe bsdur ma 2 431,2; RT1 192a6; RT3ii 186b6; RT4 297a2; RT5 277a3

RT1/2/3i/6; RT3ii; RT4; RT5

gsum pa de dag gi dbye ba dper brjod na $\mid$ gnyis las

\section{[1.2.3.1]}

Rigs gter dpe bsdur ma 1 422,9; Rigs gter dpe bsdur ma 2 431,3; RT1 192a6; RT3ii 186b6; RT4 297a2; RT5 277a3-6 (up to gsum la sgrub ${ }^{7 \mathrm{RT} 5}$; the end of this subsection is on the missing folio $277 \mathrm{~b}$ ) 


\begin{tabular}{|c|c|c|}
\hline \multicolumn{3}{|c|}{ RT1/2/3i/6; RT3ii; RT4; RT5 } \\
\hline \multicolumn{2}{|l|}{ dang po sgrub byed 'phen pa dang $\mid \mathrm{mi}$ 'phen par dbye ba ni $\mid$} & 1 \\
\hline RT1v/2v/6v; RT3ii; RT4; RT5 & RT1/2/3i/6 & \\
\hline $\begin{array}{l}\text { rang bzhin 'bras bu mtshan nyid de } \| \\
\text { mi dmigs gsum gyis sgrub mi 'phen } \|\end{array}$ & $\begin{array}{l}\text { rang bzhin 'bras bu' i mtshan nyid de } \| \\
\text { mi dmigs gsum gyis bsgrub mi 'phen } \|\end{array}$ & \\
\hline \multicolumn{3}{|c|}{ RT1/2/3i/6; RT3ii; RT4; RT5 } \\
\hline \multirow{2}{*}{\multicolumn{2}{|c|}{$\begin{array}{l}\text { sa phyogs na bum pa ma dmigs pa'i phyir med par thal zhes pa'i rang bzhin mi dmigs pa (I1) dang }\left.\right|^{*} \\
\text { *<RT5: ni sa phyogs na bum pa ma dmigs pas [me]d par thal ces brjod na | pha rol gyis sa phyogs na bum pa } \\
\text { snang rung yod par grub bam ma grub / dang po ltar na dmigs par yang ma grub pas shes 'dod med la | phyi ma } \\
\text { ltar na thal ba'i dam bcwa la bsal pa med cing rang rgyud kyi phyogs chos mi ' grub pa'i phyir ro } \|>\end{array}$}} & 2 \\
\hline & & 3 \\
\hline \multirow{2}{*}{\multicolumn{2}{|c|}{ 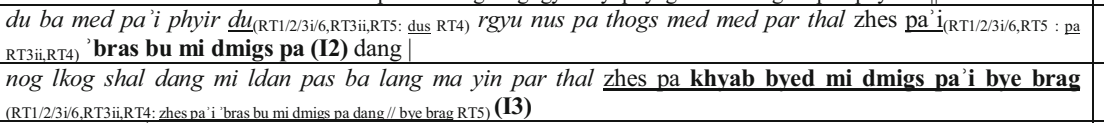 }} & 2 \\
\hline & & \\
\hline \multicolumn{2}{|c|}{ gsum la sgrub $^{\mid \mathrm{RTS}}$ byed 'phen pa mi rung ste| } & \\
\hline \multicolumn{2}{|c|}{ 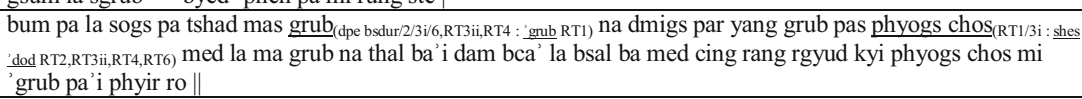 } & 3 \\
\hline \multicolumn{3}{|l|}{$\begin{array}{l}\text { lhag ma yang dag gtan tshigs kun } \| \\
\text { sgrub byed 'phen par shes par bya } \|\end{array}$} \\
\hline RT1/2/6 & RT3i; RT3ii; RT4 & \\
\hline $\begin{array}{l}\text { sngar bshad pa'i yang dag gi rtags nyi shu pos sgrub } \\
\text { byed 'phen par shes par bya'o } \|\end{array}$ & $\begin{array}{l}\text { sngar }{ }^{\alpha} \text { bshad pa'i yang dag gi rtags nyi shu las rang } \\
\text { bzhin dang 'bras bu dang khyab byed mi dmigs pa'i } \\
\text { bye brag mtshan nyid mi dmigs pa dang gsum gyi } \\
\text { lhag ma sgrub byed 'phen par shes par bya'o // }\end{array}$ & 2 \\
\hline
\end{tabular}

${ }^{\alpha}$ In RT4 (297a6), sngar is followed by a series of line-filling dots. The sentence continues with bshad pa'i yang dag on $297 \mathrm{~b} 1$

\section{[1.2.3.2]}

Rigs gter dpe bsdur ma 1 423,3; Rigs gter dpe bsdur ma 2 431,16; RT1 192b3; RT3ii 187a4; RT4 297b2

\section{RT1/2/3i/6; RT3ii; RT4}

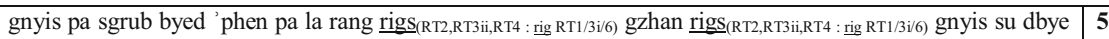
na

\section{[1.2.3.2.a]}

Rigs gter dpe bsdur ma 1 423,4; Rigs gter dpe bsdur ma 2 431,7 6; RT1 192b4; RT3ii 187a4; RT4 297b2; RT5 278b1 (from ${ }^{\mathrm{RT} 5}$ ba mo'i reg pas; beginning of the subsection missing) 


\begin{tabular}{|c|c|c|}
\hline RT1v; RT3i; RT3ii; RT4 ${ }^{\alpha}$ & RT1/6; RT2v; RT6v & \\
\hline $\begin{array}{l}\text { bzlog pa } \\
\text { (dpe bsdur/2/3i,RT3ii,RT4 : pas RT1v) rang rigs } \\
\text { phen pa bzhi } \|\end{array}$ & bzlog pa rang rigs 'phen pa Inga $\|$ & 6 \\
\hline \multicolumn{3}{|c|}{ RT1/2/3i/6; RT3ii; RT4 } \\
\hline \multicolumn{2}{|c|}{ 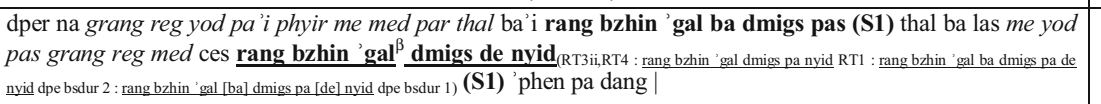 } & 7 \\
\hline RT1/3i; RT3ii; RT4 & RT2; RT6 & \\
\hline & $\begin{array}{l}\text { gran reg yod pa'i phyir tsandan gyi me med par thal } \\
\text { ces rang bzhin 'gal ba'i khyab bya dmigs pas (S5) } \\
\text { tsandan gyi me yod pa'i phyir grang reg med ces } \mid \mathbf{d e} \\
\text { nyid (S5) 'phen pa dang | }\end{array}$ & \\
\hline RT1/2/3i/6 & RT3ii; RT4; RT5 & \\
\hline $\begin{array}{l}\text { ba mo'i reg pa yod pa'i phyir tsandan gyi me med par } \\
\text { thal zhes khyab byed 'gal ba'i khyab bya dmigs } \\
\text { pas (S2) } \mid \text { tsandan gyi me yod pas ba mo'i reg pa med } \\
\text { ces 'gal dmigs de nyid (S2) 'phen pa dang } \mid\end{array}$ & $\begin{array}{l}\text { RTSI ba mo'i reg pas tsan dan }\left(4: \text { : }{ }_{\text {san }} \mathrm{RTS}\right) \text { gyi me 'gog } \\
\text { pa'i khyab byed 'gal ba'i khyab bya dmigs pas } \\
\text { (S2) | tsan dan gyi mes ba mo'i reg pa 'gog pa de } \\
\text { nyid (S2) dang | }\end{array}$ & 8 \\
\hline $\begin{array}{l}\text { spu long byed pa yod pa'i phyir } \mid \text { du ba med par thal } \\
\text { zhes pa'i rgyu dang 'gal ba'i 'bras bu dmigs pas } \\
\text { (S3) du ba yod pas spu long byed (dpe bsdur/RT2/3i/6 : phyed } \\
\text { RT1) pa med ces pa'i 'gal dmigs de nyid (S3) 'phen pa } \\
\text { dang | }\end{array}$ & $\begin{array}{l}\text { spu long byed pa'i bye brag yod pas du ba 'gog pa'i } \\
\text { rgyu dang 'gal ba'i 'bras bu dmigs pas (S3) } \mid d u \\
\text { bas spu long 'gog pa de nyid (S3) dang } \mid\end{array}$ & 9 \\
\hline RT1/2/3i/6 & RT3ii; RT4; RT5 & \\
\hline $\begin{array}{l}\text { ltos bcas yin pas ma nges par thal zhes pa'i phan } \\
\text { tshun spangs pa'i khyab byed 'gal ba dmigs pas } \\
\text { (S4a) }\end{array}$ & $\begin{array}{l}\text { ltos bcas yin pas ma nges par thal ces pa'i phan } \\
\text { tshun spangs pa'i 'gal bas khyab pa dmigs pas } \\
\text { (S4b) }\end{array}$ & \\
\hline RT1/2/6 & RT3i; RT3ii; RT4; RT5 & \\
\hline $\begin{array}{l}\text { nges pas ltos bcas ma yin zhes de nyid (S4a) ces } \\
\text { 'phen pa'o } \|\end{array}$ & $\begin{array}{l}\text { ltos med kyis ma nges pa 'gog pa de nyid 'phen } \\
\text { bsdur 1-RT3i,RT3ii,RT4,RT5 : 'phel dpe bsdur 2-RT3i) } \\
\text { ba'o } \|\end{array}$ & \\
\hline
\end{tabular}

"Van der Kuijp (1993a, p. 284, n. 13) confirms the reading "bzhi" for RT3i. The reading of RT2 is unclear. Rigs gter dpe bsdur ma 1 gives the variant "bzhi" without indicating its source, and Rigs gter dpe bsdur ma 2 ascribes the reading "bzhi" to RT2, which I suspect to be a mistake for RT3i

${ }^{\beta}$ Rigs gter dpe bsdur ma 2 marks here the beginning of the passage in RT2 and RT6 starting with "grang reg yod pa'i phyir," which seems unlikely.

\section{$[1.2 .3 .2 . b]$}

Rigs gter dpe bsdur ma 1 423,18; Rigs gter dpe bsdur ma 2 432,10; RT1 193a1; RT3ii 187b1; RT4 297b6; RT5 278b3

\begin{tabular}{|c|c|c|}
\hline RT1 $1_{\mathrm{v}} / 2_{\mathrm{v}} / \mathbf{6}_{\mathrm{v}}$; RT1/2?/6 & RT3i; RT3ii; RT4; RT5 & \\
\hline gzhan rigs 'phen pa bcu drug yod $\|$ & gzhan rigs 'phen pa bcu bzhi yod $\|^{\alpha}$ & 11 \\
\hline
\end{tabular}

${ }^{\alpha}$ Van der Kuijp (1993a, p. 284, n. 13) confirms the reading "bcu bzhi" for RT3i. According to Rigs gter dpe bsdur ma 2, the variant " $b c u$ bzhi" is the reading of RT2. This is probably an editorial mistake. Rigs gter dpe bsdur ma 1 correctly identifies the source of the variant "bcu bzhi" as RT3i 


\section{[Part A]}

Rigs gter dpe bsdur ma 1 423,18; Rigs gter dpe bsdur ma 2 432,10; RT1 193a1; RT3ii 187b1; RT4 297b6; RT5.1 278b3-279b2; RT5.2 279b2-3 (from ${ }^{\text {RT5.2Г }}$ med pa'i phyir)

\begin{tabular}{|c|c|c|}
\hline \multicolumn{2}{|c|}{ RT1/2/3i/6; RT3ii; RT4; RT5.1 } & \\
\hline \multicolumn{2}{|c|}{ 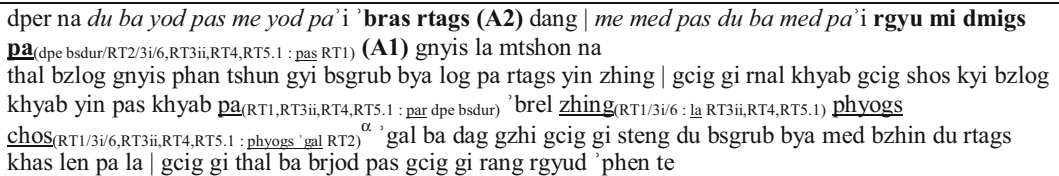 } & 12 \\
\hline RT1/2/3i/6; RT5.2 & RT3ii; RT4; RT5.1 & \\
\hline $\begin{array}{l}\text { me }{ }^{\mathrm{RTS}}{ }^{2} \text { med pa'i phyir du ba med par thal zhes rgyu } \\
\text { mi dmigs pa'i (A1) thal bas du ba yod pa'i phyir me } \\
\text { yod ces 'bras rtags (A2) kyi rang rgyud 'phen la }\end{array}$ & $\begin{array}{l}\text { me med pa'i phyir du ba med par thal zhes rgyu } \\
\text { mi dmigs pa'i (A1) thal bas du ba yod pa'i phyir } \\
\text { me yod } \\
\text { (AT3ii,RT4 : yod par thal RT5.1) ces 'bras rtags } \\
\text { (A2) 'phen la }\end{array}$ & \\
\hline $\begin{array}{l}\text { "du ba yod pa'i phyir me yod par thal zhes 'bras } \\
\text { rtags (A2) kyi thal bas me med pa'i i phyir du ba med } \\
\text { ces rgyu mi dmigs pa } \\
\text { rgyud du 'phen no } \|\end{array}$ & $\begin{array}{l}\text { du ba yod pa'i phyir me yod par thal zhes 'bras } \\
\text { rtags (A2) kyi thal bas me med pas du ba med } \\
\text { ces rgyu mi dmigs pa (A1) gnyis dang }\end{array}$ & 14 \\
\hline $\begin{array}{l}{ }^{*}<(5.2) \text { : du me khegs bzhin du yod pa'i phyir smra ba } \\
\text { la }>\end{array}$ & & 14 \\
\hline
\end{tabular}

${ }^{\alpha}$ This variant in RT2 is only indicated in Rigs gter dpe bsdur ma 1

\section{[Part B]}

Rigs gter dpe bsdur ma 1 424,7; Rigs gter dpe bsdur ma 2 432,20; RT1 193a4; RT3ii 187b3; RT4 298a4; RT5.1 279a1-6; RT5.2 279b3-6 


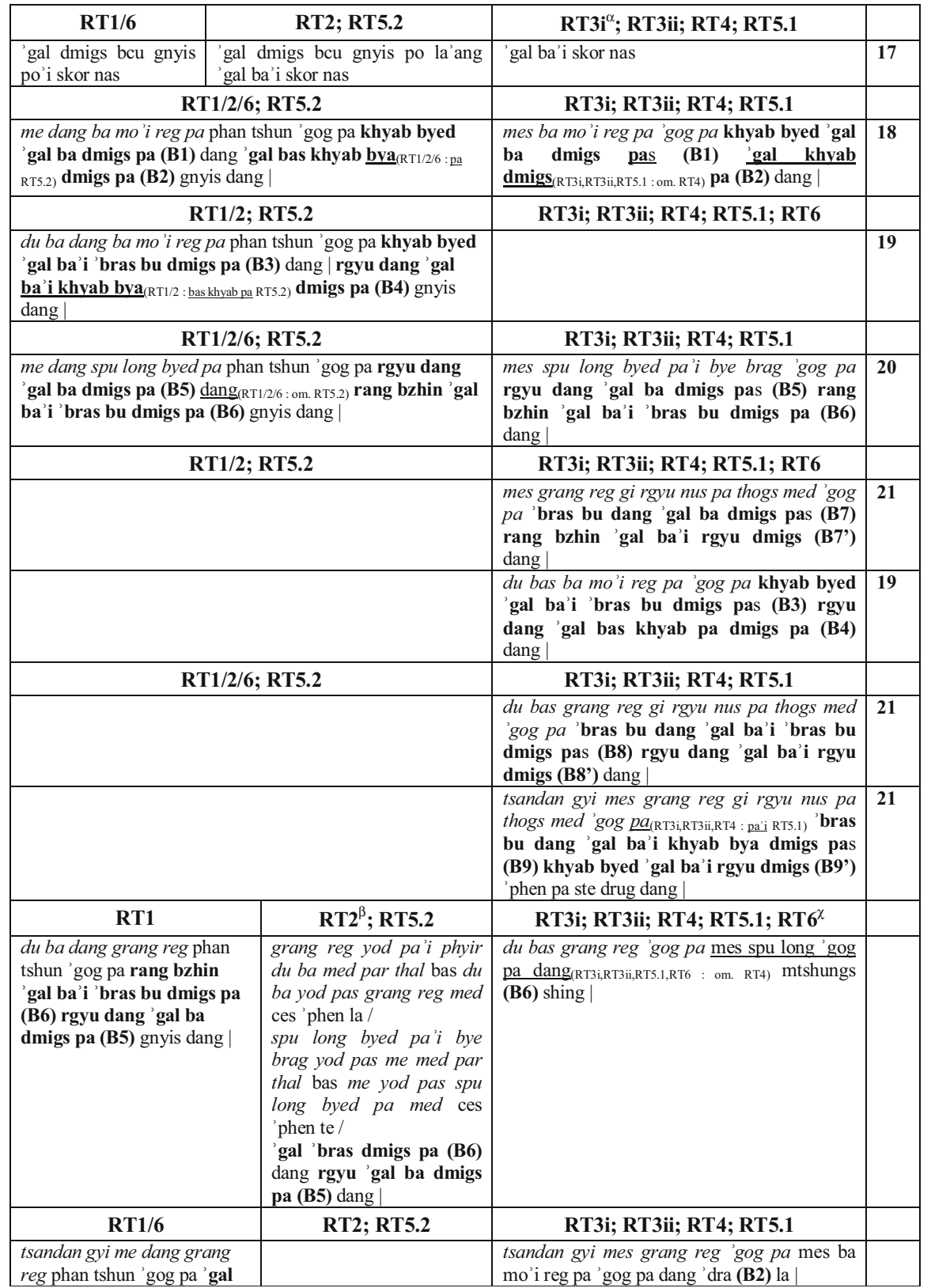




\begin{tabular}{|l|l|l|}
\hline $\begin{array}{l}\text { ba'i khyab bya dmigs pa } \\
\text { (B2) dang | khyab byed 'gal } \\
\text { ba dmigs pa (B1) gnyis } \\
\text { dang } \mid\end{array}$ & \\
\hline \multicolumn{1}{|c|}{ RT1/6 } & RT2; RT5.2 & \multicolumn{1}{|c|}{ RT3i; RT3ii; RT4; RT5.1 } \\
\hline $\begin{array}{l}\text { tsandan gyi me dang spu long } \\
\text { byed } \mid \text { phan tshun 'gog pa } \\
\text { rgyu dang 'gal ba'i khyab } \\
\text { bya dmigs pa (B4) dang } \mid \\
\text { khyab byed dang 'gal ba'i } \\
\text { 'bras bu dmigs pa (B3) } \\
\text { gnyis dang } \mid\end{array}$ & $\begin{array}{l}\text { tsandan gyi mes spu long 'gog pa } \text { du bas ba } \\
\text { mo'i reg pa 'gog pa dang mtshungs pa (B4) } \\
\text { ste gsum dang } \mid\end{array}$ \\
\hline \multicolumn{2}{|c|}{ RT1/2/6; RT5.2 } & \multicolumn{1}{|c|}{ RT3i; RT3ii; RT4; RT5.1 } \\
\hline \multicolumn{2}{|c|}{} & $\begin{array}{l}\text { phan tshun spangs pa'i skor nas } \\
\text { byas pas rtag dngos 'gog pa'i khyab byed } \\
\text { 'gal ba dmigs pas (B10) ma byas pas mi rtag } \\
\text { pa 'gog pa'i 'gal khyab dmigs pa (B10') } \\
\text { dang } \mid\end{array}$ \\
\hline
\end{tabular}

${ }^{\alpha}$ Rigs gter dpe bsdur ma 1 and 2

do not indicate where the variant in RT3i start. Rigs gter dpe bsdur ma 2 marks it as an addition after Part C in RT1

${ }^{\beta}$ In Rigs gter dpe bsdur ma 2 the text of RT2 is mistakenly marked as an addition to the passage mentioning $\mathrm{B} 4$ and B3 in RT1. Rigs gter dpe bsdur ma 1 specifies that it stands instead of the portion of RT1 mentioning B6, B5, B2, B1, B4, B3

${ }^{\chi}$ Rigs gter dpe bsdur ma 2 marks the text of RT6 as an addition to the text mentioning B2 and B1 in RT1. I take this to be a mistake

\section{[Part C]}

Rigs gter dpe bsdur ma 1 425,1; Rigs gter dpe bsdur ma 2 43318; RT1 193b1; RT3ii 188a2; RT4 298a5; RT5.1 279a6-b2; RT5.2 279b6-280a2

\begin{tabular}{|c|c|c|}
\hline RT1/2/6; RT5.2 & RT3i; RT3ii; RT4; RT5.1 & \\
\hline 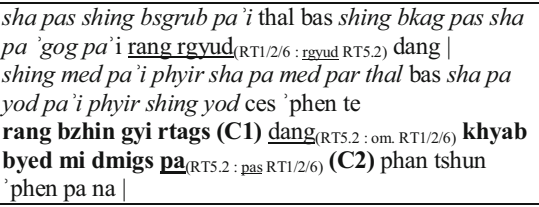 & $\begin{array}{l}\text { sha pas shing sgrub pa'i rang bzhin gyi thal bas } \\
\text { (C1) shing bkag pas sha pa 'gog pa'i khyab byed } \\
\text { mi dmigs pa (C2) dang ! } \\
\text { shing med kyis sha pa 'gog pa'i khyab byed mi } \\
\text { dmigs pa'i thal bas (C2) sha pas shing sgrub pa' } \mathrm{i} \\
\text { rang bzhin gyi rtags (C1) gnyis la }\end{array}$ & 16 \\
\hline \multicolumn{2}{|c|}{ RT1/2/6; RT3i; RT3ii; RT4; RT5.1; RT5.2 } & \\
\hline gcig gi rjes 'gro'i khyab pa gcig gi & & \\
\hline
\end{tabular}

\section{References}

\section{Tibetan sources}

bKa' gdams gsung 'bum bKa' gdams gsung 'bum phyogs sgrig thengs dang po/gnyis pa/gsum pa/bzhi pa. Ed. dPal brtsegs bod yig dpe rnying zhib 'jug khang. Chengdu: Si khron mi rigs dpe skrun khang, Vols. 1-30: 2006; vols. 31-60: 2007; vol. 61-90: 2009; vol. 91-120: 2015.

sGron ma mTshur ston gZhon nu seng ge, Tshad ma shes rab sgron ma. Ed. by Pascale Hugon, Wien, 2004: Arbeitskreis für tibetische und buddhistische Studien - Universität Wien (Wiener Studien zur Tibetologie und Buddhismuskunde 60). 
bsDus pa gTsang nag pa brTson 'grus seng ge, Tshad ma rnam par nges pa'i ți ka legs bshad bsdus pa. Otani University Tibetan Works Series, Volume II, Kyoto, 1989: Rinsen Book Co.

bsDus pa gnyis pa Bla ma dam pa bSod nams rgyal mtshan, sDe bdun gyi snying po rigs pa'i de kho na nyid rab tu gsal ba zhes bya ba bsdus pa gnyis pa. In Bla-ma Dam-pa Bsod-nams-rgyal-mtshan gyi bka' 'bum. Dehradun, 1999: Sakya College, 931-1137.

bsDus pa che ba Bla ma dam pa bSod nams rgyal mtshan, bsDus pa che ba rigs pa 'i de kho na nyid rnam par nges pa. In Bla-ma Dam-pa Bsod-nams-rgyal-mtshan gyi bka' 'bum. Dehradun, 1999: Sakya College, 673-930.

rNam rgyal Chu mig pa Seng ge dpal, gZhan gyi phyogs thams cad las rnam par rgyal ba. In bKa' gdams gsung 'bum, vol. 87, 315-448.

Pham byed gSer mdog pạ̣ chen Sākya mchog ldan, Tshad ma rigs pa'i gter dgongs rgyan lung dang rigs pa'i 'khor los lugs ngan pham byed. In The Complete Works (gSung 'bum) of gSer mdog pan chen Śākya mchog ldan. Ed. Kunzang Tobgey, Timphu, 1975 [Reprint: Nagwang Topgyal, Delhi, 1988], vol. 9 (Ta).

'Bras spungs dkar chag 'Bras spungs dgon du bzhugs su gsol ba'i dpe rnying dkar chag, 2 Vols. Ed. dPal brtsegs bod yig dpe rnying zhib 'jug khang. Beijing, 2004: Mi rigs dpe skrun khang.

Mun sel Phya pa Chos kyi seng ge, Tshad ma yid kyi mun pa sel pa. In bKa' gdams gsung 'bum, vol. 8, 434-626.

Rigs gter dpe bsdur ma 1 Sa skya Pạdita Kun dga' rgyal mtshan, Rigs gter rtsa 'grel dpe bsdur ma bzhugs. Chengdu, 2005: Si khron dpe skrun tshogs pa, Si khron mi rigs dpe skrun khang (Gangs ljongs rig gnas gter mdzod, Shes bya'i gter bum 1).

Rigs gter dpe bsdur ma 2 Sa skya Pạ̣dita Kun dga' rgyal mtshan, Sa skya gong ma rnam lnga'i gsung 'bum dpe bsdur ma las sa pan kun dga' rgyal mtshan gyi gsung pod gsum pa bzhugs / Sa skya bka' 'bum dpe bsdur ma las sa pan kun dga' rgyal mtshan gyi gsung 'bum pod gsum pa bzhugs so. Beijing, 2007: Krung go'i bod rig pa dpe skrun khang.

Rigs gter nyi snying Rong ston Shes bya kun rig (sMra ba'i seng ge), Tshad ma rigs pa'i gter gyi rnam bshad nyi ma'i snying po. In Kun mkhyen rong ston chen po 'i bka' 'bum, vol. 9 (tha), sKye dgu mdo, 2004: Gangs ljongs rig rgyan gsung rab par khang.

Rigs gter nyi ma Glo bo mkhan chen bSod nams lhun grub, sDe bdun mdo dang bcas pa'i dgongs 'grel tshad ma rigs pa'i gter gyi 'grel pa'i rnam bshad rigs lam gsal ba' i nyi ma. Ed. by rDo rje rgyal po in Tshad ma rigs gter gyi 'grel pa. Xinning (Qinghai), 1991: Krung go'i bod kyi shes rig dpe skrun khang, 1-262.

Rigs pa grub pa 'U yug pa rigs pa'i seng ge, bsTan bcos tshad ma rigs pa'i gter gyi rgyan rigs pa grub pa. In gSung 'bum / 'U yug pa rigs pa'i seng ge, vol. 1. Beijing, 2007: Krung go'i bod rig pa dpe skrun khang.

Rigs gter rnam bshad rGyal tshab rje Dar ma rin chen, Tshad ma rigs pa'i gter gyi rnam bshad legs par bshad pa'i snying po. Ed. by G. Dreyfus in collaboration with Sh. Onoda in: A Recent Rediscovery: Rgyal-tshab's Rigs gter rnam bshad: A Facsimile Reproduction of a Rare Blockprint Edition. Kyoto, 1994 : Nagata Bunshodo (Biblia Tibetica 2).

Rigs gter 'phro ba g.Yag ston Sangs rgyas dpal, sDe bdun gyi dgongs 'grel tshad ma rigs pa'i gter gyi de kho na nyid gsal bar byed pa rigs pa' $i$ 'od stong 'phro ba. Ed. g. Yag 'jam in Bod kyi bcu phrag rig mdzod chen mo, dpal ldan sa skya pa’i gsung rab, vol. 16 (tshad ma). Beijing, 2004: Mi rigs dpe skrun khang and mTsho sngon mi rigs dpe skrun khang.

Rigs gter rab gsal Go rams pa bSod nams seng ge, Tshad ma rigs pa'i gter gyi dka' ba'i gnas rnam par bshad pa sde bdun rab gsal. In Sa skya bka' 'bum: The Complete Works of the Great Masters of the Sa skya Sect of the Tibetan Buddhism (sDe dge ed.), compiled by bSod nams rgya mtsho, Tokyo, 1968-1969: Tōyō Bunko, vol. 12 (Ga).

RT1 Sa skya Pandita Kun dga' rgyal mtshan, Tshad ma rigs pa 'i gter and Tshad ma rigs pa 'i gter gyi rang 'grel. In dPal ldan sa skya pa 'i bka' 'bum - The Collected Works of the Founding Masters of Sa-skya, Reproduced from the 1736 Derge Edition, vol. 11 (da). New Delhi, 1993: Jayyed Press.

RT3ii Sa skya Pạ̣ita Kun dga' rgyal mtshan, Tshad ma rig (sic) gter gyi rang 'grel, TBRC W1CZ2047. [Tibetan library catalogue No. 004796].

RT4 Sa skya Pạ̣dita Kun dga' rgyal mtshan, Tshad ma rigs gter gyi rtsa 'grel dang rang 'grel. The root text and autocommentary of Tshad ma rigs gter, fundamental work on Buddhist logic by Sa-skya Pandita-kun-dga'-rgyal-mtshan. Reproduced from rare gold on indigo from the library of H.H. the Sa-skya Khri-'dzin. Dehradun, 1985: Sakya centre.

RT5 Sa skya Pạ̣dita Kun dga' rgyal mtshan, Tshad ma rigs pa'i gter ces bya ba 'i rang 'grel. NGMPP ref. 15252, reel no. L179/10. 
Tshad ma rigs pa'i snang ba Bo dong pạ̣ chen Phyogs las rnam rgyal, Tshad ma rigs pa'i snang ba. In Bo dong phyogs las rnam rgyal gyi gsung 'bum, vol. 8. In Encyclopedia Tibetica: The collected works of Bo-don Pan-chen Phyogs-las-rnam-rgyal, ed. S.T. Kazi. New Delhi, 1969-1981: Tibet House.

Tshad ma'i don bsdus pa Blo gros mtshungs med, Tshad ma 'i don bsdus pa, bKa' gdams gsung 'bum, vol. 87, 587-708.

\section{Modern Studies}

Hugon, P. (2008). Trésors du raisonnement. Sa skya Pandita et ses prédécesseurs tibétains sur les modes de fonctionnement de la pensée et le fondement de l'inférence. Edition et traduction annotée du quatrième chapitre et d'une section du dixième chapitre $d u$ Tshad ma rigs pa'i gter. Wien: Arbeitskreis für Tibetische und Buddhistische Studien (Wiener Studien zur Tibetologie und Buddhismuskunde 69.1 and 69.2).

Hugon, P. (2013). Phya pa Chos kyi seng ge on Argumentation by Consequence (thal 'gyur): The nature, function, and form of consequence statements. Journal of Indian Philosophy,41(6), 671-702.

Hugon, P. (2015). Text re-use in early Tibetan epistemological treatises. Journal of Indian Philosophy, 43 (4), 453-491.

Hugon, P. (2016a). Phya pa Chos kyi seng ge on Argumentation by Consequence (thal 'gyur) (2): The analysis of the correspondence between a consequence and its reverse form and the thirteenfold typology of consequences. Journal of the International Association of Buddhist Studies, 39, 51-113.

Hugon, P. (2016b). Phya pa Chos kyi seng ge and his successors on the classification of arguments by consequence (thal 'gyur) based on the type of the logical reason. Journal of Indian Philosophy,44(5), 883-938.

Jackson, D. (1983). Notes on two early printed editions of Sa-skya-pa works. The Tibet Journal,8(2), 324.

Jackson, D. (1987). The Entrance Gate for the Wise (Section III). Sa-skya Pandita on Indian and Tibetan Traditions of Pramāṇa and Philosophical Debate. Wien: Arbeitskreis für Tibetische und Buddhistische Studien (Wiener Studien zur Tibetologie und Buddhismuskunde 17.1 and 17.2).

Jackson, D. (1991a). Sources for the study of Tibetan Pramāṇa traditions preserved at the Bihar Research Society, Patna. In E. Steinkellner (Ed.), Studies in the Buddhist epistemological tradition. Proceedings of the second Dharmakirti conference, Vienna, June 11-16, 1989 (pp. 97-106). Wien: Verlag der Österreichischen Akademie der Wissenschaften.

Jackson, D. (1991b). Fragments of a "Golden" manuscript of Sa-skya Pandita's works. The Tibet Journal,16(1), 3-33.

Kellner, B. (1997). Types of incompatibility (' $\mathrm{gal} \mathrm{ba}$ ) and types of non-cognition ( $\mathrm{ma} / \mathrm{mi}$ dmigs) in early Tibetan tshad ma literature. In H. Krasser, M. T. Much, E. Steinkellner, \& H. Tauscher (Eds.), Tibetan studies: Proceedings of the 7th seminar of the international association for Tibetan Studies, Graz 1995 (pp. 495-510). Wien: Verlag der Österreichischen Akademie der Wissenschaften.

Onoda, Sh. (1986). Phya pa Chos kyi seng ge's classifications of Thal 'gyur. Berliner Indologische Studien, 2, 65-85.

Sakai, M. (2018). On Dharmakīrti's notion of contingency/dependence, with a special focus on vināśa. Journal of Indian Philosophy, Online first, 24 January 2018.

van der Kuijp, L. (1983). Contributions to the development of Tibetan Buddhist epistemology. Wiesbaden: Franz Steiner Verlag.

van der Kuijp, L. (1984). Marginalia to Sa-skya Pạ̣ita's Euvre. Journal of the International Association of Buddhist Studies, 7(1), 37-55.

van der Kuijp, L. (1986). Ldong-ston Shes-rab-dpal and a Version of the Tshad-ma rigs-pa'i-gter in thirteen Chapters. Berliner Indologische Studien, 2, 51-64.

van der Kuijp, L. (1993a). Two Mongol Xylographs (Hor par ma) of the Tibetan Text of Sa skya Pandita's Work on Buddhist Logic and Epistemology. Journal of the International Association of Buddhist Studies, 16(2), 279-298.

van der Kuijp, L. (1993b). Apropos of some recently recovered manuscripts Anent Sa skya Pandita's Tshad ma rigs pa'i gter and Autocommentary. Berliner Indologische Studien, 7, 149-162. 